\title{
ESPACIOS DE INTERACCIÓN SOCIAL Y CONFIGURACIÓN DE HÁBITOS JUVENILES DE LECTURA Y ESCRITURA
}

Por:

\author{
Giovanna Carvajal Barrios ${ }^{1}$ \\ Profesora asociada \\ Escuela de Comunicación Social \\ Universidad del Valle \\ giovanacarv@hotmail.com
}

\section{Resumen:}

El artículo parte de una investigación cualitativa sobre prácticas de lectura y escritura de cinco estudiantes universitarios. Plantea que los sujetos se constituyen en consumidores y productores de cultura en escenarios de interacción social, cuyas dinámicas dotan de sentido lo que reciben y construyen en el entramado de la vida cotidiana y en un entorno tecnologizado y mediatizado. En este proceso de configuración de perfiles de consumo y producción cultural, los jóvenes configuran su relación con la lectura y la escritura, de acuerdo con agendas definidas por la familia y la escuela en tanto espacios claves de interacción social.

Palabras claves: lectura, escritura, jóvenes, consumo cultural, producción cultural, formas de sociabilidad.

\begin{abstract}
:
This article begins of a qualitative research on reading and writing practices of five college students. Argues that the subjects constitute themselves consumers and producers of culture in social interaction stages, whose dynamics give meaning what they receive and build in the framework of a daily life and a technologized and mediated environment. In this profile's configuration process of cultural consume and production, young people shapes their relations with the reading and writing, in accordance with agendas shaped by the family and the school as key spaces of social interaction.
\end{abstract}

Key words: reading, writing, young people, cultural consume, cultural production, forms of sociability. 
La segunda etapa fue la realización de las entrevistas a los cinco estudiantes seleccionados. Con la entrevista se pretendía, principalmente, incentivarlos a que hablaran sobre los eventos significativos relacionados con sus prácticas de consumo y producción cultural, las experiencias importantes de su formación como lectores y escritores, la presencia en ellas de figuras activadoras o inhibidoras, el lugar que hoy en día ocupan en su vida la lectura, la escritura y el consumo de productos culturales de distinto orden, así como los rasgos característicos de sus prácticas de consumo y producción cultural cuando ya había transcurrido un año de ingreso a la universidad.

\section{Escenarios de interacción social y constitución de sujetos consumidores y productores de bienes simbólicos}

Una de las tesis centrales que articuló el trabajo de investigación se expresa en los siguientes términos: Los sujetos consumidores y productores de cultura se constituyen como tales en escenarios de interacción social, cuyas dinámicas dotan de sentido lo que se recibe y lo que se construye en el entramado de la vida cotidiana y en un entorno tecnologizado y mediatizado.

A partir de sus experiencias en la familia, en el barrio y en la escuela, y de su contacto con las Tecnologías de Información y Comunicación, los jóvenes se van perfilando como sujetos productores y consumidores de cultura. Es en dichos espacios de interacción social -el ámbito familiar, las actividades del barrio, el espacio escolar, los grupos de pares, el entorno masmediático e informatizadoy como consecuencia de los cruces que se dan entre éstos, que los jóvenes van construyendo sus hábitos de consumo y producción cultural.

Lo que sucede en los distintos espacios de interacción social -sus dinámicas y transformaciones, así como las relaciones que se producen entre ellos- define, en gran medida, el lugar que la escritura, la lectura, los medios de comunicación audiovisual y las tics ocupan en la vida de los jóvenes informantes. Los cruces, las transversalidades y las superposiciones entre los diferentes escenarios son un rasgo clave dentro de la configuración de prácticas de producción y consumo cultural.

Desde la perspectiva de esta investigación, es importante inscribir los trayectos de producción y de consumo cultural de los jóvenes en un horizonte general en el que la familia, la escuela y el barrio constituyen las claves para comprender la manera como se han constituido sus formas de relacionarse con la lectura, la escritura y, en un sentido más amplio, con los diversos bienes culturales a los que tienen acceso. Según Sonia Muñoz, las prácticas de consumo cultural se erigen sobre la base de "dimensiones de socialidad"; por eso su estudio no puede limitarse al tipo de bien al cual tienen acceso las personas o al tiempo del que disponen para su disfrute, sino que ha de considerar también "la natural inscripción de dicha práctica en una comunidad específica -familiar, vecinal, de amigos- que la modela por los modos de comunicación que produce"(Muñoz, 1995, p. 8). 
Si consideramos que los escenarios de interacción social son los espacios donde se genera la construcción de sentido, podemos afirmar entonces que las distancias, las tensiones, pero también las superposiciones entre los distintos escenarios en los que interactúan los sujetos determinan -en última instancia- las variaciones en las formas de sentido que allí se construyen. En otras palabras, las negociaciones y tensiones que el sujeto mantiene en estos diferentes escenarios para acceder a diferentes recursos simbólicos y culturales (adaptarse al grupo de pares, aprender lo que le enseñan en la escuela, atender y acatar los valores promovidos por la familia, insertarse en la camaradería barrial, apropiarse de los modelos televisivos, etc.) constituyen una experiencia educativa en la que se va forjando un sujeto que hace selecciones de un conjunto de ofertas culturales, define prioridades de consumo, precisa estilos y gustos, configura modos de producción de sentido, en otras palabras, se forma como lector y escritor, como consumidor de productos audiovisuales, y en un sentido más general, como consumidor y productor de bienes simbólicos.

A partir de lo anterior es posible postular la existencia de un trabajo educativo que trasciende al dispositivo escolar y en el que se van perfilando lectores y escritores particulares.

Por ello, tiene sentido estudiar estas tensiones y juegos del sujeto resolviendo demandas y optando por determinadas ofertas culturales que vienen de estos diferentes escenarios y espacios de interacción.

El recorrido realizado en la investigación permitió comprender el modo en que se fueron configurando las prácticas de consumo y producción cultural de los jóvenes entrevistados, particularmente las relacionadas con la lectura, la escritura y el uso de las tecnologías audiovisuales de la comunicación.
Muchos de los cambios que tuvieron lugar en sus vidas (desplazamientos al interior o por fuera de la ciudad, traslados de una institución escolar a otra, transformaciones en la estructura familiar o innovaciones en el equipamiento tecnocultural de los espacios en los que los jóvenes actuaban) influyeron de una u otra manera en su interés -o desinterés- por determinadas prácticas de lectura y escritura, así como en la configuración de sus hábitos de producción y consumo cultural.

\section{Los medios como generadores de ambientes}

La importancia de los espacios de interacción social en los que se inscriben las prácticas de consumo y producción cultural de los jóvenes se conecta con otra de las tesis centrales que articularon la investigación: los medios de comunicación, más que transmitir contenidos y textos, proveen a los receptores de determinados ambientes, y su efectividad radica en la capacidad que tengan para sumergirlos en ellos. Lo que han hecho todos los medios, desde la palabra oral hasta los lenguajes informáticos, pasando por el arte en sus distintas manifestaciones, el libro, el cine, la radio, la televisión, la discoteca, el ciberespacio, en fin, todos aquellos que han surgido a través de la historia, es actuar como ambientes en los que las personas nos sumergimos temporalmente: la música nos aleja de las actividades de otros y estimula nuestra sensibilidad; la lectura nos conduce por senderos recorridos por los personajes de una historia y nos hace penetrar en sus conciencias hasta el punto de saber qué sienten o qué piensan; la televisión nos transporta a otros lugares reales o ficticios; el cine nos hace vibrar con las historias que crea para nosotros; el poema nos hace vivir la nostalgia, la angustia, el gozo o la esperanza...

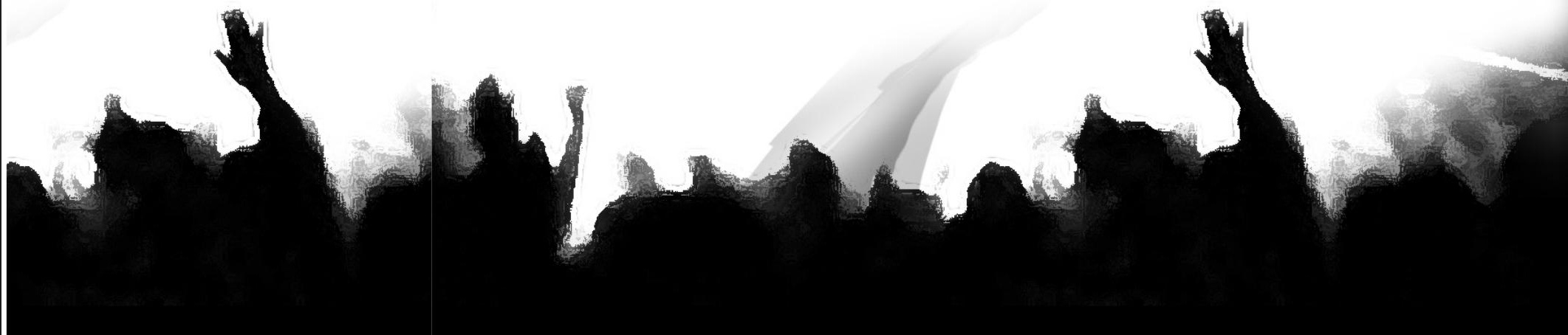


Pero ese efecto de encubrimiento que resulta de nuestra inmersión en ellos sólo es posible en virtud de la existencia de un entramado social en el que los medios se inscriben y en el que se lleva a cabo la producción de sentido. Por eso, si por un lado afirmamos que los medios actúan como generadores de ambientes, gracias a que se inscriben en formas de interacción social, sostenemos también que éstas afectan a los medios y dan lugar a la transformación de los mismos tanto en su estructura, como en el modo en que son incorporados por las personas a sus vidas. Por lo anterior, la clave para entender el lugar que los medios ocupan en la vida de las personas, particularmente en la de los jóvenes, no está ni en los dispositivos mismos, ni en los contenidos que canalizan, sino en las relaciones sociales que les dan sentido.

En resumen, partimos aquí de que las formas de interacción social pueden reforzar o frenar la eficacia comunicativa de los medios en su dimensión ambiental. Hechos como la falta de apetito lector de algunos jóvenes, la apatía frente a las nuevas tecnologías por parte de otros, el rechazo de un medio como la televisión, el repliegue a los espacios privados para la recepción de cine, el auge de un dispositivo tecnológico como el mp3 o el Ipod, nos hablan de algo más que de un problema de contenidos. Se trata, entonces, de entender los medios desde las formas de relación social que los encarnan, que hacen posible su empleo y su presencia como generadores de ambientes, que les dan sentido.

\section{Los jóvenes y sus trayectos de vida: recorridos, desplazamientos y permanencias}

Desde la perspectiva de esta investigación, la relación específica entre experiencias de vida de los jóvenes y configuración de sus hábitos de lectura y escritura se manifiesta de dos maneras: en primer lugar, en la presencia de adultos que se han encargado de transmitirles un capital cultural ${ }^{7}$ y de estimular en ellos diferentes formas de producción y consumo cultural. En segundo lugar, en las huellas que han dejado en sus propios textos y en sus gustos como lectores, experiencias significativas sucedidas en el transcurso de sus vidas.

Hacer una reconstrucción de los desplazamientos y los trayectos realizados por los jóvenes a lo largo de sus vidas permitió identificar aquellos eventos significativos relacionados directa o indirectamente con la inauguración de prácticas de consumo y producción cultural o con la transformación de las mismas. Con la denominación "recorridos, desplazamientos y permanencias", se hace referencia a los cambios en el lugar de residencia (el traslado de una ciudad a otra, del campo a la ciudad o de un sector a otro de la misma), pero también a los viajes, los recorridos urbanos y los eventos que ocurren como consecuencia de los cambios de residencia, por ejemplo el paso de un colegio a otro. Como pudo constatar la investigación, la mayor parte de los desplazamientos espaciales de los jóvenes están directamente relacionados con periodos de crisis o con cambios cruciales en las estructuras familiares, casi siempre la separación de los padres o la necesidad de un cambio de tutor para mitigar los efectos de la crisis familiar en el niño o el adolescente. 
En la medida en que los desplazamientos de los jóvenes se relacionan con transformaciones significativas en sus vidas -pues son a la vez causa y consecuencia de las mismas-, pueden ser considerados como uno de los factores que inciden en la constitución de perfiles juveniles de producción y consumo cultural, particularmente en lo relacionado con las prácticas de lectura y escritura. Una visión detallada de los relatos biográficos de los estudiantes permitió identificar algunas claves en la configuración de sus hábitos de lectura y escritura, sin que por ello se las presente como causas únicas o absolutas.

Los desplazamientos implican, por una parte, una desconexión, una desvinculación de contextos donde se han tejido relaciones sociales y afectivas (el barrio, el colegio, la familia, los grupos de pares), y por otra parte, un proceso de reinstalación y de reubicación en nuevos contextos (otros amigos, otros compañeros de estudio, otros tutores de crianza, otras actividades y experiencias). Estos procesos fueron importantes para esta investigación no sólo -y no necesariamente- porque la lectura y la escritura cumplan la función de reactualizar y prolongar los vínculos anteriores, o la de contribuir al proceso de adaptación y vinculación efectiva al nuevo contexto ${ }^{8}$, sino también porque tales desplazamientos traen consigo un 'relevo' de las figuras -adultas o jóvenes- significativas en la configuración de perfiles de consumo y producción cultural. Un cambio de ciudad, un traslado de colegio, así como una presencia permanente en un contexto urbano fuertemente mediatizado y tecnologizado, pueden llegar a promover vínculos (familiares, barriales, escolares, vida de pares que puede ser extra barrial y extra escolar), determinantes en la configuración de hábitos y rutinas de producción y consumo cultural, como se pudo corroborar en las experiencias narradas por los jóvenes entrevistados.

Algunos de los casos estudiados se caracterizaron por la permanencia en una ciudad, e incluso en el mismo barrio, mientras que otros se distinguieron por una gran movilidad. En los relatos biográficos hechos por los cinco estudiantes, fue posible identificar algunas huellas que dejó en ellos la permanencia en un barrio, el abandono de un sector de la ciudad o los tránsitos de una ciudad a otra. También fue posible ver, en algunos casos, que tales experiencias -de permanencia o de desplazamiento, de ruptura o reactualización de los vínculos- dejaron marcas en sus prácticas de consumo y producción cultural. El caso de una joven que empezó una práctica de escritura epistolar a partir de un viaje que coincidió con el divorcio de sus padres, es un ejemplo de ello. Lo es también el caso de otro joven que, al no tener un acceso regular a espacios distintos al hogar y al colegio, encontró en la televisión un refugio y una forma de organización del tiempo libre. Es importante destacar la situación vivida por este joven, puesto que para él fue crucial el paso de un estado de permanente refugio en el hogar, en el colegio y en compañía de la televisión, a un alejamiento de la casa en dos ocasiones distintas, por lapsos prolongados. En esos viajes de duración indefinida empezó a vivir situaciones determinantes: el cambio de colegio y de tutor en su primer viaje, la sensación de inadaptabilidad a su regreso, el conocimiento de situaciones novedosas para él a partir de su segundo viaje cuando se encontraba en plena adolescencia y, por último, el regreso definitivo que marcará el inicio de una etapa nueva en su vida: el ingreso a la universidad. Aquí el grado de movilidad espacial fue importante por cuanto en esos desplazamientos de una ciudad a otra o al interior mismo de la urbe, se empezaron a acumular experiencias que, por una parte, estaban relacionadas con sus preferencias en materia de música y cine, y por otra parte, fueron incorporadas a sus textos como temas o imágenes que deseaba plasmar en sus escritos. 
Además de los tiempos de permanencia y de los desplazamientos en el interior o al exterior de la ciudad, es necesario considerar las "distancias" que los jóvenes van marcando frente a espacios de interacción social como el barrio o el colegio, a medida que el tiempo transcurre y ellos se introducen en ámbitos distintos. El relativo distanciamiento con los amigos del barrio, el alejamiento de los amigos de la infancia y la adolescencia y la construcción de nuevos lazos afectivos a la par que cambian los intereses, los gustos, las expectativas, son aspectos que se pueden leer en los relatos biográficos de estos jóvenes.

La ruptura de los lazos afectivos con los amigos del barrio o del colegio coincidió, en cuatro de los casos analizados, con la aproximación a la universidad como nuevo espacio de interacción. Este es un momento crucial en la transformación de las prácticas de consumo y producción cultural de los jóvenes. El abandono de ciertas actividades y el enfriamiento de vínculos con amigos de la infancia coincide entonces con la transición a un ámbito de interacción social distinto, en el cual se llevarán a cabo estrategias de reconocimiento y vinculación al nuevo contexto. Surgen entonces nuevas experiencias para narrar, nuevas emociones que en un primer momento se cuentan a compañeros y compañeras del colegio y luego se vuelven tema de conversación con el nuevo grupo de pares. La escritura y la lectura aparecen allí como prácticas que unen, que se comparten y se convierten en objetos de intercambio. Aparecen los autores que todos deberían conocer, la prisa por el texto que no se leyó para la clase, la discusión en la cafetería sobre el trabajo para la semana siguiente. Surgen también las angustias y los placeres de la escritura; de los escritos que dejarán de ser personales y pasarán a ser públicos. El paso está dado. Nuevas subjetividades y nuevos imaginarios se construyen cuando las distancias espacial y temporal continúan editando la película de la vida que son los recuerdos.

\section{Papel de la escuela en la constitución de perfiles juveniles de producción y consumo cultural}

\section{La escuela como espacio de interacción social}

La institución escolar es un espacio de interacción social en el que los alumnos construyen vínculos con sus maestros, sus compañeros y demás personas relacionadas con el funcionamiento de la misma. Todos los relatos que los jóvenes hicieron de su tránsito por el colegio aludían de alguna manera a tales vínculos, trátese de las relaciones que establecieron con compañeros y profesores; de las formas de interacción que comprometían actividades de producción cultural -entre ellas la escritura y la lectura-; de las angustias generadas por la dificultad para entablar relaciones con otros; de la sensación de desarraigo que trae consigo el paso de una institución escolar a otra; o de la incertidumbre y desasosiego generados por la entrada a la universidad. Todos esos son síntomas de que el paso por la escuela es, sobre todo, una experiencia existencial intensa, en la que se juega permanentemente la construcción de la subjetividad. 
En términos generales, se asiste a la escuela para apropiarse de una serie de conocimientos necesarios en el desempeño del mundo adulto, al interior de una sociedad cada vez más compleja y jerarquizada. Sin embargo, más allá de la finalidad estrictamente educativa de la escuela, ésta constituye un espacio de socialización, donde se construye un entramado en el que se mueven los sujetos y en el que se sienten en cierto modo 'protegidos' hasta cuando llega el momento de asumir su rol de adultos. Salir del seno del hogar e ingresar a un ámbito social diferente en el que otras normas regulan y muchas veces pretenden borrar las diferencias; construir nuevos vínculos; empezar a establecer territorios diferenciados (la casa, el colegio, la calle); reconocer -o transgredir- los límites entre el tiempo del estudio, el del ocio y el de la vida en familia; iniciar la inevitable confrontación entre las ofertas educativas formales y las 'profanas' que ofrecen las tiras cómicas, los juegos callejeros, la vida en el barrio, la televisión, los video juegos, son sólo algunas de las consecuencias que trae consigo el ingreso del infante a la institución educativa.

Pero no sólo es trascendental el momento en el que se inicia la vida escolar; otro cambio significativo se produce cuando llega la hora de salir del espacio cerrado del colegio -caracterizado por sus certezas, sus normas, sus responsabilidades delimitadas- y enfrentar aquello que Rodrigo Parra Sandoval ha denominado "la soledad del adolescente universitario". Para este investigador, la soledad no es solamente un concepto interior, psicológico, existencial, sino que puede también ser mirada como un fenómeno social:

La naturaleza social de la soledad del adolescente universitario se centra en el debilitamiento de las relaciones significativas con las personas e instituciones fundamentales para su vida cuando hace la transición entre la cultura de la escuela secundaria, más cerrada, protectora y reglamentada, y la cultura universitaria más abierta, competitiva y laxa. Como ese tránsito de alguna manera tiene el sentido de un rito de paso entre la adolescencia y la primera edad adulta, las instituciones sociales y los actores fundamentales de esas instituciones esperan un cambio en el comportamiento del adolescente sin que algunas de las condiciones necesarias para ese cambio estén presentes. Se da entonces una situación de desprotección y conflicto con los actores adultos principales y con las instituciones que lleva a que sus relaciones se debiliten peligrosamente, lo que crea una especie de 'zona neutra' cuya característica fundamental es la soledad social (Parra, 1996, p. 219).

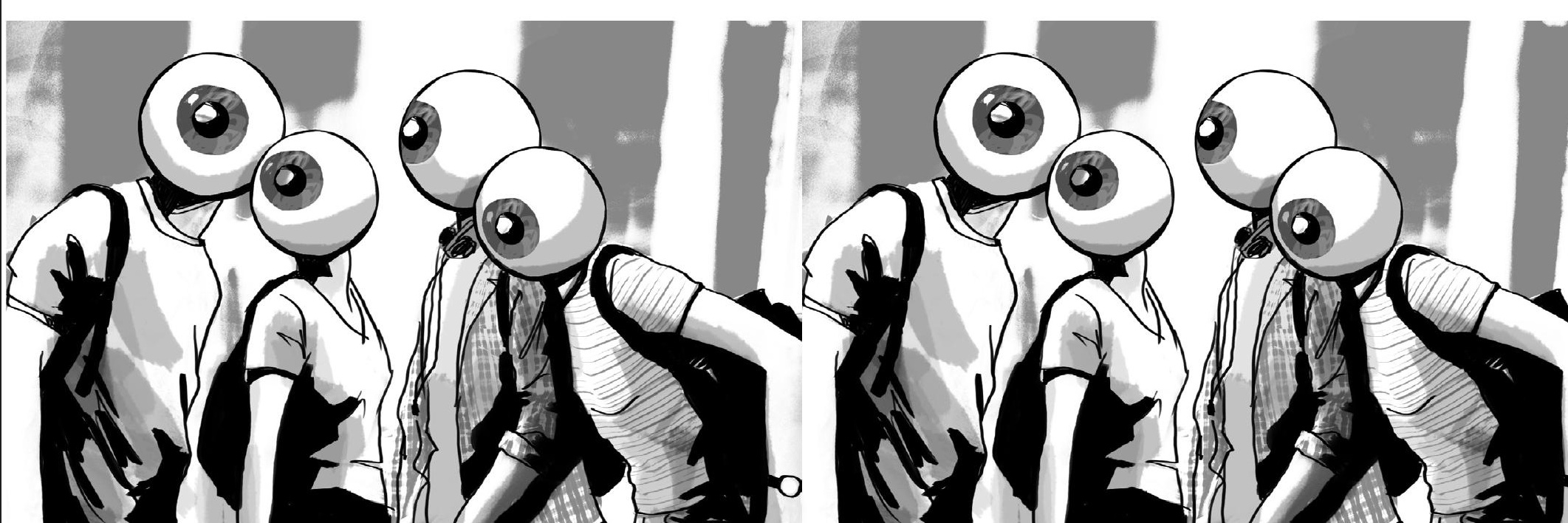


El paso por los diferentes niveles de escolaridad, además de significar la apropiación de múltiples conocimientos por parte de los alumnos, da lugar a experiencias sociales de diferentes dimensiones. La escuela, el colegio o la universidad -lugares donde niños, adolescentes y jóvenes pasan gran parte de su tiempo- son escenarios sociales en los cuales se propician formas de relacionarse que rebasan el espacio físico del plantel, para dar lugar a vínculos fuertes, algunos de los cuales perviven o conservan un sitio especial en el conjunto de recuerdos de los jóvenes, pues incluso hasta varios años después del ingreso a la universidad, muchos de ellos siguen frecuentando sus amigos del colegio.

No obstante, y pese a la importancia de la escuela como ámbito clave de interacción social, estamos asistiendo a una crisis de dicha institución: la crisis de la escuela, en tanto instrumento para la producción y distribución del saber ilustrado, que constituye, a su vez, el correlato de una crisis general de la subjetividad moderna, a la que alude Carlos Pérez en su libro "Sobre la Condición Social de la Psicología” (Pérez, 1996).

Pérez plantea que la subjetividad moderna, aquella que empezó a forjarse junto con la modernidad alrededor del siglo XII, se encuentra hoy en crisis y está dando lugar a subjetividades emergentes. Una de las consecuencias más importantes de este proceso es precisamente la crisis de instituciones como la familia y la escuela, y el afianzamiento de los medios de comunicación y del mercado global como formas de relación social, cuyo interés central es la ampliación de los niveles de consumo y el acto mismo del consumo como forma de existencia en el mundo contemporáneo.

El sujeto moderno es, según lo señala Carlos Pérez, es un individuo formado

En el marco de una familia patriarcal y monogámica donde la clara autoridad del padre es vivida como ley y hace la mediación entre los espacios clásicos, estrictamente distintos, entre lo público [la sociedad, el derecho, la escuela, el mercado de los productos, el espacio de las ideas, el de lo político] y lo privado [la familia, la ética -y la fe-, lo emotivo, lo subjetivo, la educación familiar, la autoridad del padre, de sus ideas, de su sustento]. (p. 71)

Para este autor, “en sentido estricto, en la familia clásica sólo el padre es sujeto”. Éste constituye una individualidad que contiene, al interior de su calidad de individuo, la existencia de su familia. Por esa razón es que "los demás miembros de la familia son sujetos incompletos, asociados, a lo sumo en formación que requieren de la protección legal, social y afectiva del padre. La familia es el lugar donde se viven los conflictos que constituyen a los futuros sujetos como futuros padres o como futuros miembros asociados de otras familias" (p. 71).

Para Carlos Pérez, el conflicto padre-hijo cumple, entonces, una función muy importante dentro del proceso de constitución de los sujetos, ya que significa la lucha por el derecho a una subjetividad autónoma, la cual “en tiempos clásicos sólo conseguirán los hijos varones que logren formar familias". En otras palabras, es el padre -en tanto individuo arquetípico- "el mediador entre una sociedad compuesta de individualidades y la familia, de la que éstas surgen"(p. 71). 


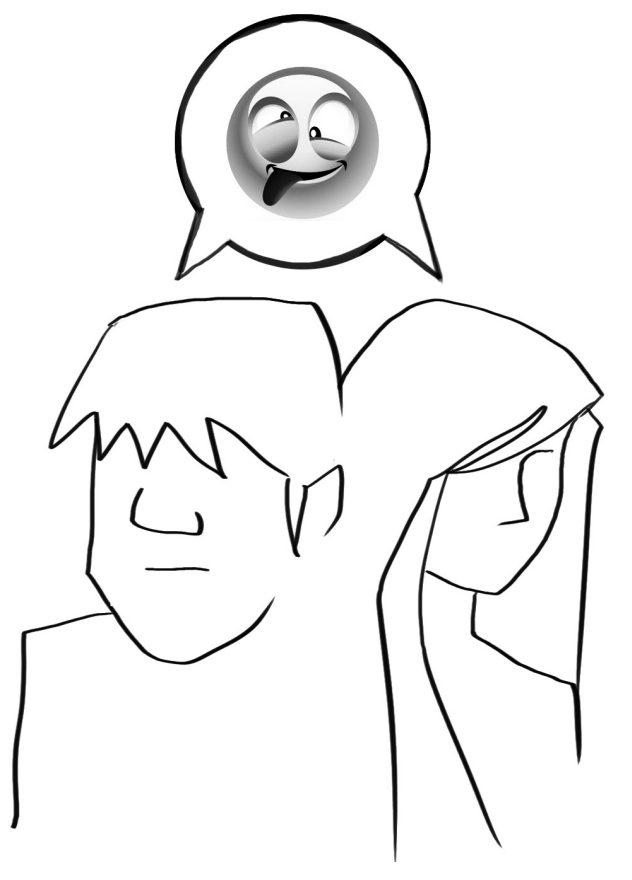

De lo planteado por Pérez interesa resaltar aquí lo siguiente: teniendo en cuenta que los demás miembros de la familia clásica siempre tuvieron un status vago y subordinado, esa vaguedad constituirá "una fuente principal de conflictos en la época de disolución de la familia clásica”(p. 72). Y lo será, en parte, porque una de las características de ese sujeto moderno es que, así como "no se sentiría completo sin una familia que regir o un ámbito de libertad en el que desplegarse, tampoco se sentiría completo sin el consumo adecuado, sin los medios adecuados para el consumo" (p. 74).

Según lo propone este autor, existen tres realidades a las que ha tenido que enfrentarse la subjetividad moderna y que han desencadenado la crisis que atraviesa actualmente: [1] "el efecto de la progresiva ampliación del consumo en el marco de la completa articulación del mercado mundial; [2] el efecto inverso sobre muy amplias capas de la población de la marginación del consumo y la integración social; [3] el efecto de la progresiva decadencia del liberalismo político y económico, ahogado por las mismas fuerzas que dicen defenderlo" (p. 80). De las tres, nos interesa en particular la primera, pues es la ampliación del consumo lo que "ha hecho posible el desarrollo de nuevas subjetividades que empiezan a competir con el sujeto clásico" (p. 80).

Como consecuencia de los avances exorbitantes del consumo y las permanentes revoluciones de la técnica, otros sujetos empezaron a emerger (la mujer, el niño, el inmigrante) y a constituirse como personas autónomas. Los efectos no se hicieron esperar:

El ingreso objetivo al espacio del trabajo y al consumo, después el acceso reclamado y conseguido a los derechos políticos y sociales, incluso la integración que se produce de hecho por la interferencia de los medios de comunicación, o por el exceso de consumo que ya no puede ser fácilmente controlado por el padre. Poco a poco, garantía por garantía, algo más que un espacio económico, social, institucional, fue ganado, algo que es significativamente más: la constitución de subjetividades diversas que aspiran a su autonomía (p.81).

Pérez aclara que la disolución de la familia clásica es un proceso independiente de la voluntad de los actores y no es una consecuencia de la comunicación, por lo cual no puede resolverse en el terreno de las relaciones personales. Por eso sostiene que a pesar de las culpas que se le puedan endilgar a la familia patriarcal monogámica (su carácter discriminatorio, injusto e inhumano), ésta tiene una lógica interna "no sólo cargada de defectos sino también de importantes virtudes que aparecían en ella de manera paradójica. Entre ellas, la de hacer posible la aparición del espacio psíquico privado de la imaginación y de la rebeldía crítica” (p. 83).

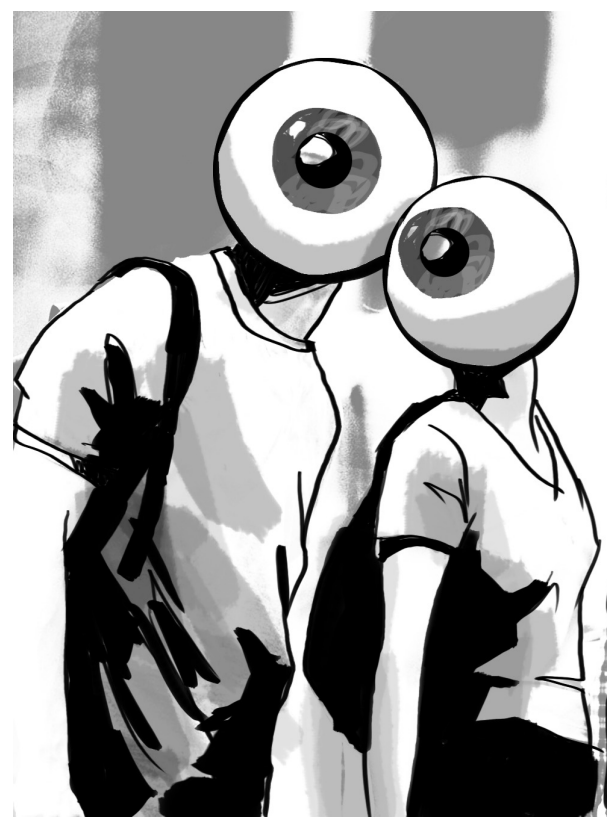


Finalmente, Pérez plantea que:

Una nueva subjetividad es promovida por la socialización primaria que salta a la familia y desplaza la autoridad del padre (ya en crisis), por la permanente revolución de las expectativas de consumo (que afecta tanto a los que consumen como a los que no), que sirven de escape a la necesidad de individuación y facilitan la pertenencia, por la diversificación creciente del mercado, que promueve la oferta de individualidades prestadas y sustitutivas, externas (p. 84).

A partir de lo expuesto por Pérez, interesa plantear aquí que la crisis de la subjetividad moderna - expresada a su vez en la crisis de la figura del padre y de la institución familiar en el sentido clásico- ha traído también como consecuencia una crisis de la institución escolar como espacio de formación de los niños y jóvenes, así como el debilitamiento de la figura del maestro, en tanto figura de autoridad al interior del ámbito escolar. Veamos en qué sentido: parte de las consecuencias de la crisis de la figura del padre, en tanto sujeto que contiene en su individualidad a los demás miembros de la familia, es precisamente que el "mundo de la edad adulta" -aquel en el que se adquiere el derecho a opinar y a expresar lo opinado, pero también el derecho a la autonomía- ya no constituye un atractivo de grandes proporciones: se quiere ser como el padre, pero al mismo tiempo se quiere seguir teniendo un padre; se quiere ser autónomo, racional, productivo, consciente, libre, pero también protegido, reconocido, mantenido, emotivo, hijo p. (81).

Lo anterior explicaría el lugar paradójico que ocupa la escuela en la vida de los jóvenes: en ella tienen protección, pero al mismo tiempo reclaman en ella autonomía; en ella viven momentos gratos, pero se trata de momentos relacionados con los vínculos sociales que allí se construyen y no tanto con la función central de la escuela como instrumento de distribución del saber y forjador de una cultura ilustrada9 . También encontramos allí la clave para entender algunas de las estrategias adoptadas por la escuela para aliviar la crisis de autoridad de los maestros y ganar la competencia que debe realizar permanentemente con las tecnologías informáticas y audiovisuales, cuyos productos resultan mucho más atractivos para los niños y adolescentes. La búsqueda de alternativas distintas de enseñanza (actividades que "dinamicen" la clase y que la hagan menos aburridora), la inclusión de los dispositivos audiovisuales en el aula (presentar videos argumentales o documentales), la promoción de relaciones maestro-alumno distintas (la figura del profesor jovial, amigo de los estudiantes, que les habla de igual a igual), pueden ser leídas como estrategias tendientes a recuperar la imagen en crisis del maestro, a lograr introducir en el proceso educativo elementos que resulten seductores a los estudiantes, y a re-posicionar la institución escolar, en tanto espacio de formación por excelencia ${ }^{10}$.

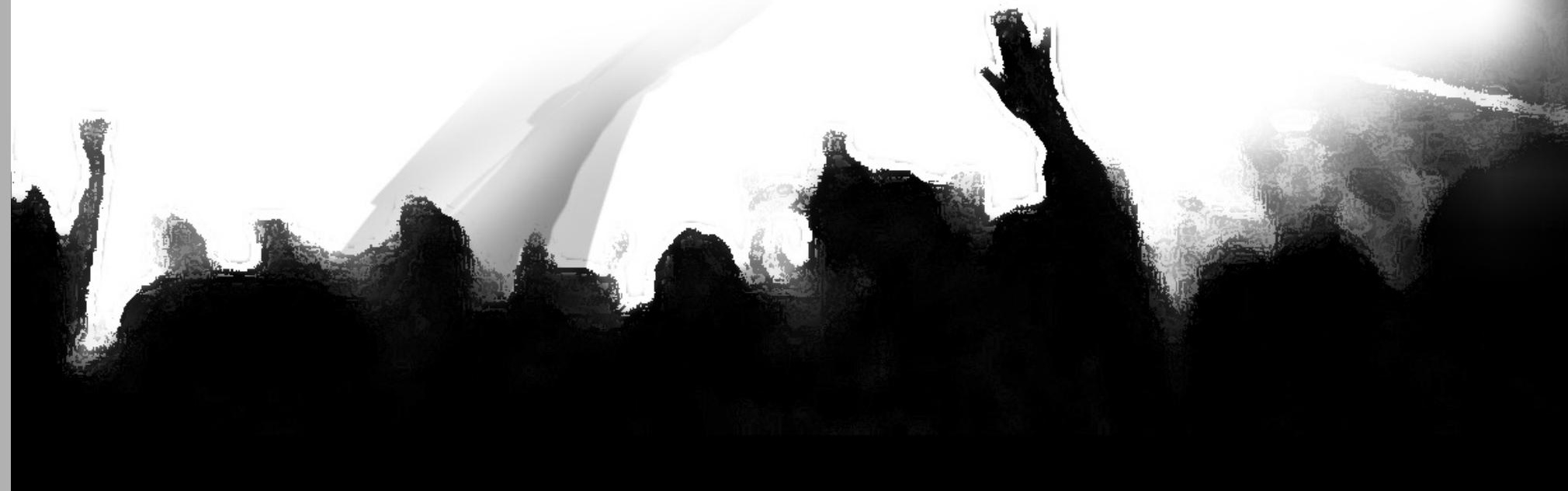




\section{La escuela y su equipamiento tecnocultural: usos y des-usos.}

Además de constituir un espacio clave de sociabilidad, la institución escolar puede ser analizada en tanto ambiente tecnologizado y mediatizado. ¿Qué tecnologías intelectuales se hacen presentes en el escenario de la escuela? ¿' ¿Cuáles son los usos dados a ellas? ¿Qué papel cumplen en la difícil tarea de restituir el status de la escuela?

\section{El uso de las tecnologías informáticas y su dimensión educativa}

En cuanto a las tecnologías informáticas, es importante destacar que ninguno de los jóvenes entrevistados atribuyó sus conocimientos en este campo a lo aprendido en el colegio. Por el contrario, todos aludían de un modo despectivo a las clases de sistemas en las que los estudiantes se entretenían con otras actividades y era poco lo que aprendían. Además, en ninguno de los colegios donde estudiaron los jóvenes se contaba con equipos actualizados que situaran a los estudiantes en un entorno tecnológico de punta; tampoco se tenía personal capacitado para la pedagogía de las nuevas tecnologías de comunicación.

Sin lugar a dudas, la manera como debiera abordarse la enseñanza de las tecnologías informáticas en los colegios es una reflexión que resulta imprescindible. ¿Es factible pensar en una pedagogía para los nuevos soportes tecnológicos? ¿Cuáles deberían ser sus rasgos característicos? ¿Por qué muchos jóvenes aprenden más sobre los usos y aplicaciones del computador cuando se sientan a "cacharrear" en él que cuando asisten a una clase de sistemas en el colegio? ¿Cómo se complementan la instrucción formal y los descubrimientos producto del juego, la experimentación, el ensayo y el error? ¿Cómo lograr la introducción de dichas tecnologías en el trabajo educativo, más allá de su uso instrumental, es decir, asumiéndolas desde los modos de inserción en la vida social y cultural de los alumnos?

Estas preguntas introducen un problema fundamental en la reflexión sobre la dimensión educativa de las tecnologías informáticas: su doble presencia en tanto herramientas para la producción y transmisión del conocimiento pero también como instrumentos que deben ser objeto de un proceso de aprendizaje. En otras palabras, su papel como mediaciones cognitivas dentro y fuera del espacio escolar ${ }^{12}$. 
Si hay algo que nos permite entender la especificidad educativa de las tecnologías informáticas es el papel central del juego y la experimentación en los procesos de apropiación de los lenguajes que vehiculan. La síntesis aprendizaje-juego y aprendizaje-experimentación quizá sea la clave donde se juegue la presencia de dichas tecnologías como objetos de aprendizaje. Según Julián Gonzálezª , la dimensión educativa de las tecnologías informáticas se compone fundamentalmente de tres rasgos: (1) el aprendizaje se lleva a cabo con el aparato, no en el aparato -como ocurriría con el carro cuando se aprende a manejar-, ni del aparato -como ocurre con el libro al apropiarse de las lecturas-; (2) se trata de un aprendizaje permanente cuya continuidad se hace posible en virtud de las destrezas y los saberes acumulados; (3), tiene como requisito fundamental la actualización permanente de los programas y el surgimiento de nuevos campos de apropiación, que hacen necesaria una continua renovación de saberes.

¿A qué podría atribuirse, entonces, el fracaso sistemático del aprendizaje de los computadores en los casos particulares a los que alude esta investigación? Para responder a esta pregunta pueden considerarse tres posibles explicaciones, todas ellas relacionadas de algún modo con la tesis central ya mencionada sobre la presencia de los medios en tanto ambientes inscritos en formas de interacción social.

La primera explicación tiene que ver con el papel desempeñado por el profesor. En los casos analizados, los profesores no parecen haber actuado como activadores en el proceso de apropiación de la tecnología, al privilegiar el aprender del (profesor) y el aprender en (el computador), sin que en este proceso se hubiera permitido un aprendizaje con (el computador), en el que el juego, la experimentación y la puesta en común de los hallazgos y descubrimientos estuvieran presentes.

La segunda explicación es que el salón de clase no constituyó un espacio que favoreciera las dinámicas de comunicación e interacción social propias de la apropiación de las tecnologías informáticas (esto, sumado al déficit de aparatos y a la limitación del rol del profesor a labores de instrucción y vigilancia). Otro planteamiento de Julián González -relacionado con ésta y con la anterior explicación- resulta pertinente en este análisis: los efectos educativos más importantes del computador están, no en el dispositivo tecnológico, sino en las dinámicas comunicacionales que genera en sus usuarios. Para González, lo que las tecnologías informáticas han conseguido es constituirse en un escenario de interacción para quienes las usan, las desean y las sueñan. En torno a estos dispositivos se traman conversaciones cotidianas y coordinaciones para usarlas, ajustarlas o recusarlas. Por eso la clave no se encuentra en el uso de las tecnologías, sino en los usos de su uso, relacionados en este caso con la acción de compartir con otros las modalidades de empleo, las cuales -más que "aprenderse"- se descubren (o como dirían los jóvenes, se "pillan"). Este conversar con y sobre las tecnologías es la dimensión educativa más importante de las tecnologías digitales, que se convierten en pre-texto y contenido de relaciones con otros ${ }^{14}$.

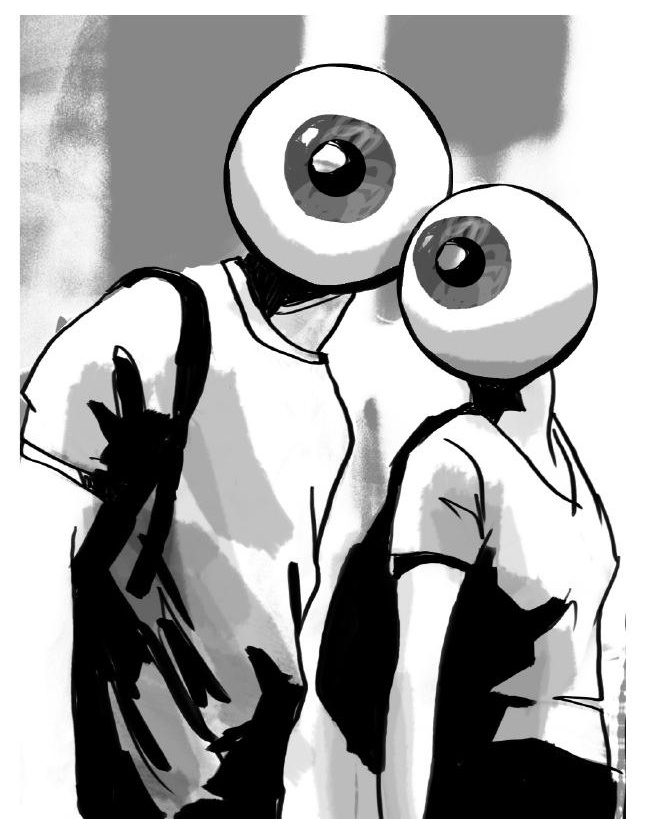


La tercera explicación posible, es que la clase no constituyó un dispositivo (espaciotemporal) suficiente para el aprendizaje. Aunque fuese necesaria la presencia de un saber adulto especializado -como sucede con la lectura y la escritura-, la información recibida a partir de la presencia del docente no parece haber sido suficiente. Habrían hecho falta periodos de práctica -de juego y experimentación- en los que el estudiante explorara y descubriera el aparato, es decir, lograra sumergirse en el ambiente que le proporcionaba el medio y viajar por él de la misma manera como se empiezan a recorrer las calles, lugares y parajes de una ciudad desconocida. En un breve ejercicio de investigación realizado a partir de la experiencia de un profesor universitario de edad madura que utiliza el computador para el trabajo intelectual y artístico, se encontraron dos aspectos significativos (Carvajal, 1996): (1) El usuario aprendió la mayoría de aplicaciones mediante el "cacharreo", incluso en aquellos programas de los cuales tenía manual. (2) El afianzamiento de los aprendizajes se daba como consecuencia de la repetición de su aplicación. Imposible aspirar, entonces, a que un aprendiz escolar que no cuenta con la tecnología asimile lo que le enseñan una vez a la semana sin tener la oportunidad de practicarlo, y sobre todo de incorporarlo a sus rutinas de trabajo, o de juego.

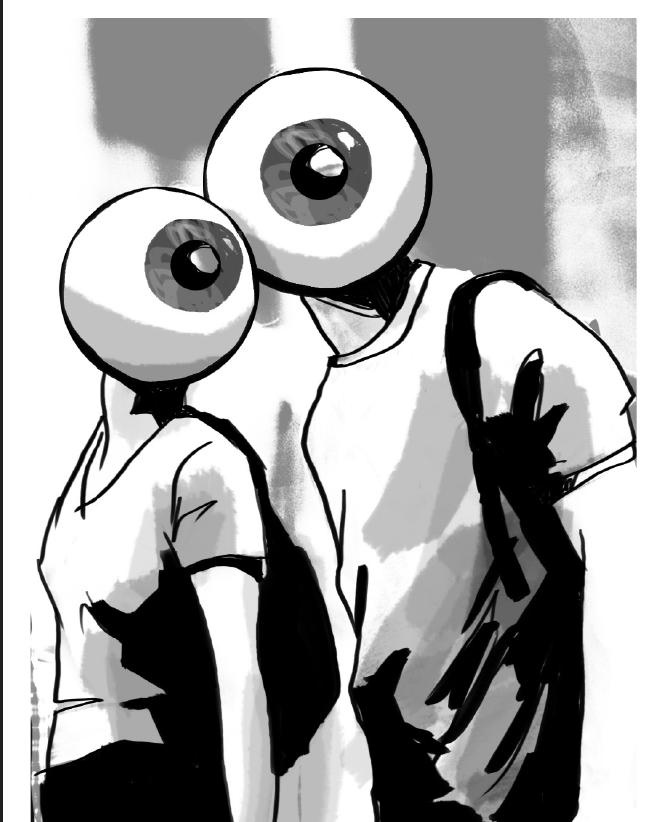

Aunque no es posible establecer generalizaciones sin hacer un estudio comparativo más detallado, lo sucedido con los estudiantes entrevistados y con el profesor universitario muestra que la apropiación de las tecnologías informáticas compromete necesariamente dinámicas de juego y de exploración (no sólo en el caso de los niños y los jóvenes) que permitan descubrir usos y posibilidades de aplicación. Esta es una de las razones por las cuales la incursión del computador en el espacio escolar en algunos casos no logra superar los linderos de la subutilización. Cuando se desconoce la dimensión comunicativa de las tecnologías, es decir, se ignora que su uso es un escenario de interacción con los otros (dentro y fuera del aula escolar), se cae en lo que Martín Barbero denomina el uso instrumental de las nuevas tecnologías; aquel que

Abstrayendo los medios de sus peculiaridades comunicativas y su densidad cultural se sirve de ellos únicamente como 'ayudas' exteriores al proceso pedagógico o como ejercicios puramente formales: se aprende a usar el computador no para insertarlo como estrategia de conocimiento sino para que el alumno pueda atestiguar que aprendió a usarlo (Martin-Barbero, 1997, p. 21). 


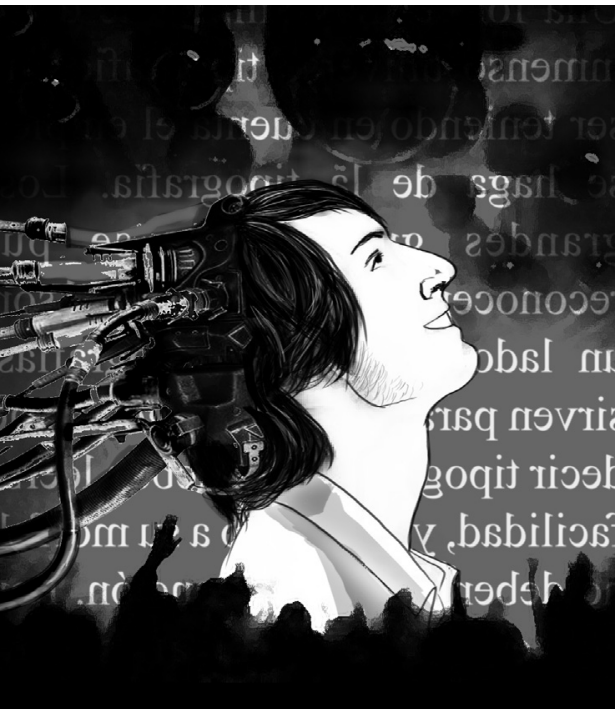

Usos del computador: entre la experiencia educativa y la dimensión ambiental

A propósito de lo planteado anteriormente con respecto a los ambientes mediáticos y a su inserción en entramados de interacción social, podemos decir que el 'cacharreo' en el computador -que equivale a la experimentación, al recorrido, y que se asemeja a la experiencia de pasear por una ciudad desconocidaexplicita claramente el carácter ambiental del computador como medio. Lo que un usuario hace cuando se enfrenta al computador es apropiarse de los lenguajes informáticos y sumergirse paulatinamente en ambientes que éste le propicia. Los libros y manuales de instrucción para apropiarse de tales lenguajes proveen al usuario de ciertas pistas para aventurarse y avanzar en los desplazamientos y recorridos. Sin embargo, una vez iniciado el trayecto, el cual puede realizarse en diversas direcciones y ritmos, el instructivo se va volviendo cada vez menos significativo, de la misma manera que el viajero abandona progresivamente el mapa a medida que conoce el itinerario de viaje.

Lo interesante es que si a un viajero o a un usuario de las tecnologías digitales se le pidiera explicar cómo conoció la ciudad o cómo aprendió una rutina informática, no podría hacerlo de una manera precisa, pues dicha solicitud traería consigo otra demanda: traducir en un lenguaje unidireccional, explicar en términos de itinerarios y recorridos lineales lo que ha sido no lineal, concurrente y no programado. En realidad, harían falta demasiadas palabras, demasiadas secuencias de oraciones para explicar cómo aprende un chico a usar y manipular un video juego o un programa de computador. Esa es una diferencia fundamental entre la dimensión educativa de las tecnologías audiovisuales y los modos en que opera el aprendizaje escolar.

Los programas de computador y los videojuegos operan como ambientes en los que los usuarios se van sumergiendo y van adquiriendo los saberes necesarios para desenvolverse en ellos, siguiendo un itinerario no previsible; su aprendizaje es casi un juego de constantes descubrimientos. En contraste, el dispositivo escolar opera de manera lineal, secuencial, programada, en función de resultados que se consideran previsibles. Incluso en aquellos casos en los que el aprendizaje de los lenguajes informáticos ha estado mediado por procesos de enseñanza formal, el 'cacharreo' forma parte esencial del proceso de apropiación de las tecnologías digitales, cuyo recorrido resulta aleatorio, pues es cada usuario quien va señalando las rutas a seguir, a medida que las va encontrando.

Durante la primera etapa, aquella en la cual se empieza a conocer el funcionamiento del aparato, es frecuente que aparezcan temores o que se experimente en ciertos momentos algún tipo de frustración, sensaciones que no necesariamente excluyen la fascinación por la tecnología o el deseo de apropiarse de ella. También es factible que tales emociones perduren durante mucho tiempo. 
Para una de las estudiantes entrevistadas, por ejemplo, no fue fácil familiarizarse con el uso del computador. Reconocía que en distintos ámbitos de la sociedad es indispensable este conocimiento, pero al mismo tiempo manifestaba sentirse desfasada o, como ella misma lo expresa, "primitiva" con relación a los adelantos contemporáneos. Era tal su falta de desenvolvimiento en tareas como la diagramación de un texto, que prefería seguir utilizando un sistema artesanal, sobre todo porque no le interesaba producir de un modo distinto los separadores de libros, las tarjetas, los cuadernos y otros artículos que hacía para la venta. Por otra parte, ella nunca había tenido una relación lúdica con el computador y su uso había estado supeditado a la necesidad de dar una buena presentación a sus trabajos de la universidad. Por eso no tenía reparos en decir que lo odiaba: "Es horrible porque como no sé manejarlo hace cosas que yo no le pido, o que no creo estarle pidiendo". Ella reconocía su fascinación por el aparato, pero al mismo tiempo tenía temor de dañarlo o de echar a perder lo que estuviera elaborando en él. Otra de las jóvenes compartía esta misma preocupación pues reconocía sentirse molesta ante su propia lentitud y torpeza para digitar textos. Y al lado de los ya mencionados, aparecieron otros temores como el de no saber resolver un problema técnico causado por una mala aplicación, o el temor a perder algún archivo por alguna equivocación.

Como ya se dijo, la etapa de iniciación en el uso de una tecnología puede también dar lugar a distanciamientos marcados que se refuerzan por una situación particular como la de no poseer el aparato. Eso fue, en gran medida, lo que le sucedió a un estudiante: después de que en su colegio se viera abocado a un proceso de aprendizaje que no produjo en él ninguna motivación, el único recuerdo que le quedó fue la inutilidad de dicha experiencia. Un recuerdo que no pudo borrarse a partir de experiencias distintas con la tecnología. Este joven reconoció durante la entrevista la importancia que tiene saber de computadores. Sin embargo, el mundo de los computadores le llamaba la atención como objeto de estudio y no como herramienta de trabajo. En otras palabras, le preocupaba más conocer sobre los nuevos modos de percepción de los que tanto escuchaba hablar en sus clases de la universidad, que introducirse él mismo en ese universo como usuario de las nuevas tecnologías.

Casi todas las potencialidades que estos cinco estudiantes le atribuían al computador tenían que ver con su uso como ordenador y no sobrepasaban el límite de las aplicaciones básicas de la tecnología. Además de las ventajas relacionadas con la escritura de textos (organización y pulcritud en la presentación de los trabajos, así como ahorro de tiempo y energía en su elaboración, posibilidad de reimprimir o revisar documentos que han sido archivados, recursos para la diagramación), sólo se mencionaron otras dos posibilidades: el acceso a la información y las facilidades que pueden ofrecer los programas especializados en áreas específicas. Ahora bien, los trayectos de vida de estos jóvenes evolucionaron en una dirección que era difícil prever en el momento de la investigación. Dos de los jóvenes que eran más reticentes al uso de las Tics hoy en día están ligados, en el ámbito profesional, al uso de dichos dispositivos tecnológicos: uno de ellos en el campo del arte digital y otro en la creación alternativa de productos multimedia.

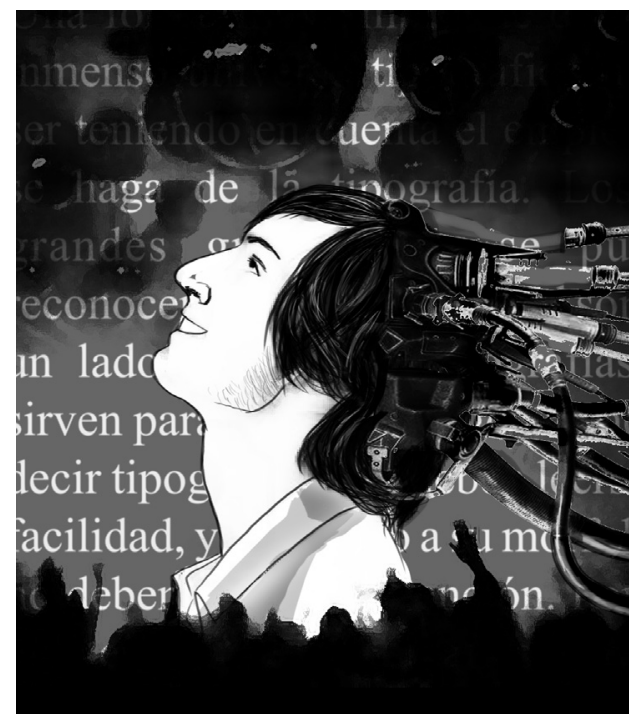




\section{Lectura y biblioteca escolar: dimensión ambiental vs uso instrumental}

La investigación sobre lecturas y escrituras juveniles encontró que el uso de la biblioteca, en tanto dispositivo tecnocultural, estaba reducido a su mínima expresión. Era un lugar al que los alumnos iban por obligación y, en casi todos los casos, la lectura que allí se realizaba no pasaba de ser un simulacro.

Como ya se ha planteado en el presente artículo, una de las principales características de la escuela es que, además de ser un espacio donde se transmiten saberes, constituye un ámbito importante de interacciones sociales, aspecto que a veces es subvalorado en las discusiones pedagógicas, en aras de las reflexiones sobre papel de la institución escolar en la formación académica y disciplinar de los individuos. Incluso, en ocasiones, suele olvidarse que la tarea misma de distribución del conocimiento ha traspasado los linderos de la escuela, pues de ella se encargan también las tecnologías audiovisuales e informáticas, las cuales sitúan el placer de ver, de jugar, de escuchar o de leer, por encima de la necesidad de aprender. Este último es un rasgo que caracteriza la dimensión educativa de los medios y las Tics, en contraste con el dispositivo escolar, que sitúa por encima del placer la necesidad de aprender.

La tarea educativa y socializadora de las tecnologías audiovisuales se enmarca en la construcción de ambientes particulares de recepción en los que los jóvenes se apropian de saberes que no necesariamente están en capacidad de verbalizar linealmente, y se construyen entramados sociales en los que cobra sentido escuchar música, navegar en internet, chatear, leer, ver televisión, videojugar, etc. La escuela tradicional, en cambio, se asemeja más a un sendero unidireccional en el que interesa dar cuenta de lo aprendido resolviendo problemas puntuales, respondiendo cuestionarios, presentando informes o aprobando evaluaciones sobre temas que podrían olvidarse después de un tiempo.

La pérdida de aura de las bibliotecas escolares es uno más de los síntomas de otra de las crisis en la que se sume la escuela. Crisis que, como lo señala Martín Barbero, parte del doble desafío que le hace el mundo audiovisual: por una parte, el desafío a la "pretensión de ser aún el único espacio legítimo de organización y transmisión de los saberes" y por otra parte, la presencia de los medios audiovisuales como "un nuevo y poderoso ámbito de socialización, esto es, de elaboración y transmisión de valores y pautas de comportamiento, de patrones de gusto y de estilos de vida” (Martin-Barbero, 1997, p. 21).

Sin embargo, ese desplazamiento de la escuela frente a las tecnologías audiovisuales, tiene menos que ver con su papel como transmisoras de contenidos, y mucho más con su condición de ambientes y su inscripción en formas de interacción social al interior de las cuales las personas -niños, jóvenes o adultos- construyen saberes. 
Un rasgo fundamental que diferencia las tecnologías audiovisuales de la institución escolar es que los saberes construidos en las primeras son eficaces en la medida en que se trata de saberes no instrumentales, es decir, que no se adquieren con el fin de resolver problemas particulares o de acopiar un conocimiento. En el caso particular de la lectura, Barthes ofrece una definición que resulta útil para comprender este planteamiento: las lecturas instrumentales son aquellas que se necesitan "para la adquisición de un saber, de una técnica, y en las que el gesto de leer (sic) desaparece bajo el acto de aprender"

(Barthes, 1984, p.).

Esta distinción entre un tipo de lectura instrumental y un tipo de lectura por el placer de leer nos permite entender la diferencia entre la dimensión educativa contenida en una práctica de consumo cultural cualquiera-en la que prima el gesto y el placer de 'leer' y la dimensión escolar, pedagógica -instrumental- en que se privilegia el saber sobre el placer de leer. Es importante aclarar que cuando hablamos de leer, no solamente nos referimos al libro; también la música, el cine, la publicidad, los videojuegos, son 'leídos' por nosotros. Pues bien, cuando ese habitar en el ambiente de las prácticas escolares (la lectura, la escritura, los ejercicios, las tareas) es subordinado a la obligación de saber, el leer se instrumentaliza como se instrumentaliza también el programa de televisión o la película de cine, integrados al aula de clases-, es decir, se escolariza. El saber derivado de la escuela tiende a ser un saber funcional, para resolver problemas y contestar las preguntas. En ese sentido, la experiencia en el aula de clases se asemeja más al desplazamiento por un laberinto, cuyo recorrido es siempre unidireccional. El tipo de saber derivado de los ambientes tecnológicos y mediáticos es distinto. Los jóvenes aprenden -son educados- en formas de saber que ellos mismos no siempre podrían verbalizar, porque no se trata de saberes lineales sino de saberes en los que se juntan unos datos con otros solidariamente.
La lectura de los conventos, los internados y las cárceles, pero también las veladas populares en las que la gente del pueblo se reunía a escuchar relatos en la voz de quienes sabían leer; la lectura que se hacía en las fábricas de tabaco en Cuba "en las que mientras los obreros torcían las hojas de tabaco se leían relatos políticamente edificantes y folletinescos" (MartinBarbero, 1997, p. 20); los ritos de iniciación en la lectura realizados por los padres en las noches, antes de dormir, de los que habla Daniel Pennac en su libro "Como una novela"; son sólo algunas muestras de la inserción del texto impreso en una trama de interacciones sociales en que se han inscrito y han adquirido sentido las prácticas de lectura.

$\mathrm{Si}$ queremos identificar las transformaciones relacionadas con la crisis de la lectura (específicamente de ciertos tipos de lectura), tendremos que referirnos a la crisis de los ambientes y al entramado de relaciones sociales que propiciaban ciertos modos de leer, así como al surgimiento y transformación de algunos medios y tecnologías de comunicación que se insertan en interacciones sociales distintas. La radio, la televisión y el cine han sufrido transformaciones paulatinas que ponen en evidencia la relación entre medios de comunicación, ambientes y formas de sociabilidad. Así, hemos pasado de la escucha grupal de la radio al uso del transistor portátil; de la audición colectiva de música a la individualización del consumo mediante el uso de dispositivos móviles como el mp3 y el ipod; de la recepción televisiva en familia a la recepción privada en la habitación. Los empresarios de distribución de cine, a su vez, descubrieron que el cine es ante todo ambiente y se dedicaron a intervenirlo hace dos décadas en este sentido: re diseñaron las salas (multicines, cinesbar, cines en los centros comerciales, salas pequeñas para favorecer una oferta más diversificada) y con ello re diseñaron los ambientes de recepción, para lograr atraer a los otrora espectadores asiduos de cine y reposicionar un medio que se había visto sensiblemente afectado por el surgimiento de la televisión y posteriormente del video. 
En el caso específico de la lectura, una reactivación de la lectura de libros debiera, entonces, pasar por la re invención y el diseño de los ambientes de lectura. De hecho, la aparición de materiales en soportes electrónicos (páginas web, enciclopedias multimedia, conversaciones en internet) está significando la transformación de la lectura como ambiente e invita a lanzarse al reto de transformar los ambientes escolares de lectura, homologados en la mayoría de los casos al recinto de la biblioteca, a la lectura interior en el asiento individual, o a la lectura en voz alta como forma de seguimiento de la prácticas lectoras. ¿Cómo deberían ser los nuevos ambientes escolares en los que ha de inscribirse la lectura? ¿Cuáles son los rasgos del entramado social en que debe enmarcarse su práctica? ¿Es factible pensar en la transformación del dispositivo escolar en un 'ambiente' donde se asuma la educación como un proceso que integra prácticas de consumo y producción cultural diversas y en el que se integre un registro más amplio de inteligencias? ${ }^{15}$ Estos interrogantes sugieren la necesidad de realizar trabajos orientados a rediseñar el dispositivo escolar en una dirección que integre la noción de las Tics y los medios de comunicación como ambientes y considere su inscripción en formas de interacción social, dentro de las cuales se lleva a cabo la construcción de sentido.

La reflexión sobre el papel cumplido por la biblioteca en el contexto de la formación escolar hace necesario mencionar dos hechos que se relacionan entre sí. En primer lugar la pérdida del status del libro como depósito de saber, y en segundo lugar, el diseño de estrategias para la utilización de la biblioteca, por parte de la institución escolar. La exigencia de una o dos horas de "lectura o de "biblioteca" a la semana -presente en varios de los casos analizados en esta investigación- busca de alguna manera restituir ese status perdido del libro. De igual manera, la utilización del espacio de la biblioteca para hacer tareas asignadas (resúmenes, investigaciones, cuestionarios, etc.) o para tener allí a los alumnos cuando un profesor no puede asistir a sus clases, funciona como una estrategia de aconductamiento, acorde con los rasgos que desde una cierta postura deberían caracterizar las prácticas de la lectura y la escritura escolar, como por ejemplo, ser silenciosas, disciplinadas, atentas. En este sentido, la biblioteca sería el 'ambiente' propicio para la lectura, o mejor, el ambiente que se adecúa a un tipo particular de lectura.

Recordemos que la formación en prácticas de escritura y de lectura modernas implicó la presencia de una serie formas de disciplinamiento (control de la postura corporal, rutinas de vigilancia y seguimiento de las prácticas de lectura, establecimiento de normas relacionadas con el cuidado de los libros, de las instalaciones y del mobiliario de la biblioteca, etc.) que eran efectivas porque se sumaban al prestigio social de las figuras adultas portadoras de saber, tales como los padres, los maestros o las directivas de la institución escolar. La escritura y la lectura significaban el ingreso al mundo adulto caracterizado, como ya vimos, por el derecho a expresar las opiniones. Hoy, ante la crisis de la subjetividad moderna, expresada a su vez en la crisis de las figuras de autoridad y del mundo adulto como un mundo anhelado ${ }^{16}$, la biblioteca escolar constituye un dispositivo que intenta, a partir de estrategias no muy diversas, la recuperación del status del libro como instrumento de saber y el de ella misma como templo por excelencia de la lectura. 


\section{La familia: primer espacio promotor de prácticas de consumo y producción cultural}

A partir de lo encontrado en esta investigación, es posible plantear que la familia funciona como dispositivo de socialización de prácticas de consumo cultural en un doble sentido:

(1) porque es el espacio donde se produce el primer tipo de mediación adulta que el niño tiene en su conocimiento del mundo; y (2) porque constituye un lugar en el que los bienes simbólicos se convierten en objetos de comunicación.

La familia es, en otras palabras, uno de los ámbitos donde circula y se concreta el consumo cultural. Durante la infancia, los padres y los demás adultos que rodean al niño, por intermedio de las prácticas de consumo cultural que promueven, lo van conduciendo a un determinado entorno, relacionado con el equipamiento tecnocultural al que tiene acceso el grupo ${ }^{17}$ y con los usos que se hagan del mismo. Con la entrada del niño al colegio y con su acceso al barrio o al conjunto residencial como espacio de interacción social, esas tendencias de consumo y de producción cultural se van transformando, dando lugar a hábitos que pueden distanciarse en mayor o menor medida de los de sus padres, tutores de crianza, familiares u otros adultos cercanos. En otras palabras, las prácticas de producción y consumo cultural de los jóvenes oscilan y se transforman de acuerdo con los contextos en los que éstos se mueven. Así, en su diario vivir pueden entremezclarse prácticas promovidas por el ámbito familiar con aquellas privilegiadas en espacios como el colegio o la universidad, los grupos de amigos, la vida del barrio, entre otros, y el peso de cada una puede ir variando en las distintas etapas de su vida.

El consumo es, como se planteó al hacer referencia a la crisis de la subjetividad moderna, el lugar donde se produce la emergencia de otras subjetividades. Es en el terreno del consumo donde las nuevas subjetividades logran gran parte de su autonomía, pues éste puede permitir el acceso al mundo adulto, sin que necesariamente se hayan superado las etapas de la infancia y de la adolescencia. Por ejemplo, pese a los controles que la familia y la escuela intentan imponerles, los niños y los jóvenes son independientes de los adultos cuando practican los videojuegos, ven televisión o navegan en internet. Sin embargo, a partir de lo relatado por los estudiantes, es posible ver que los adultos siguen ocupando un lugar importante en la constitución de los hábitos de producción y consumo cultural de los menores. El estímulo de diversas actividades al interior de la vida familiar -como el dibujo, la lectura y la asistencia al cine- constituye una forma importante de manifestar el cariño hacia los hijos, los sobrinos o los hermanos menores, lo cual puede resultar determinante para la configuración de rutinas de consumo y de producción cultural. 
Lo anterior ratifica la validez de una de las tesis centrales desarrolladas en el presente trabajo: las prácticas de producción y consumo cultural se encuentran inscritas en formas particulares de interacción social que las dotan de sentido. En el caso de la familia, ésta se encarga de promover el desarrollo de ciertas prácticas que, como ya dijimos, serán la base de los futuros hábitos de producción y consumo cultural de los jóvenes. No obstante, es necesario tener en cuenta que los hábitos estimulados en la infancia no constituyen por sí mismos factores definitivos en la conformación de dichos patrones de consumo, y que al lado de la familia se encuentran instancias socializadoras como el barrio y el colegio que también tienen una incidencia significativa en este proceso. Por esta razón, es posible que con el transcurrir de los años, los gustos de los jóvenes en materia de consumo ya no coincidan tanto con los de sus padres o familiares mayores. Ahora bien, esto no implica el surgimiento de distancias insalvables o la pérdida de contacto con los mayores con quienes ya no se comparten las mismas prácticas de consumo.

Además de promover actividades que estimulen de manera directa la lectura y la escritura (comprar cuentos a los niños, leérselos cuando ellos aún no pueden hacerlo por sí mismos -y aún después-, propiciar el intercambio de correspondencia), existen otras estrategias -explícitas o implícitaslas cuales incentivan ciertos hábitos de consumo y producción cultural en los niños. Este conjunto de estrategias da lugar a lo que aquí denominamos una agenda cultural doméstica. Se trata de una agenda que regula el uso del tiempo, que establece una jerarquía de actividades (en términos de secuencias y durabilidad), que selecciona unas y descarta otras. Permitir que el niño vea toda la televisión que quiera o, por el contrario, restringir el tiempo dedicado a la recepción de este medio; controlar el acceso a internet y el uso del celular; asistir con regularidad a espectáculos públicos; programar jornadas diarias de lectura antes de ir a dormir; incentivar la audición de cuentos y música infantil; dotar el espacio doméstico de artefactos como los video juegos y la reproductora de video para que los hijos no tengan que salir a la calle a buscar diversión; todos ellas son actividades que están reguladas por esa agenda cultural doméstica.

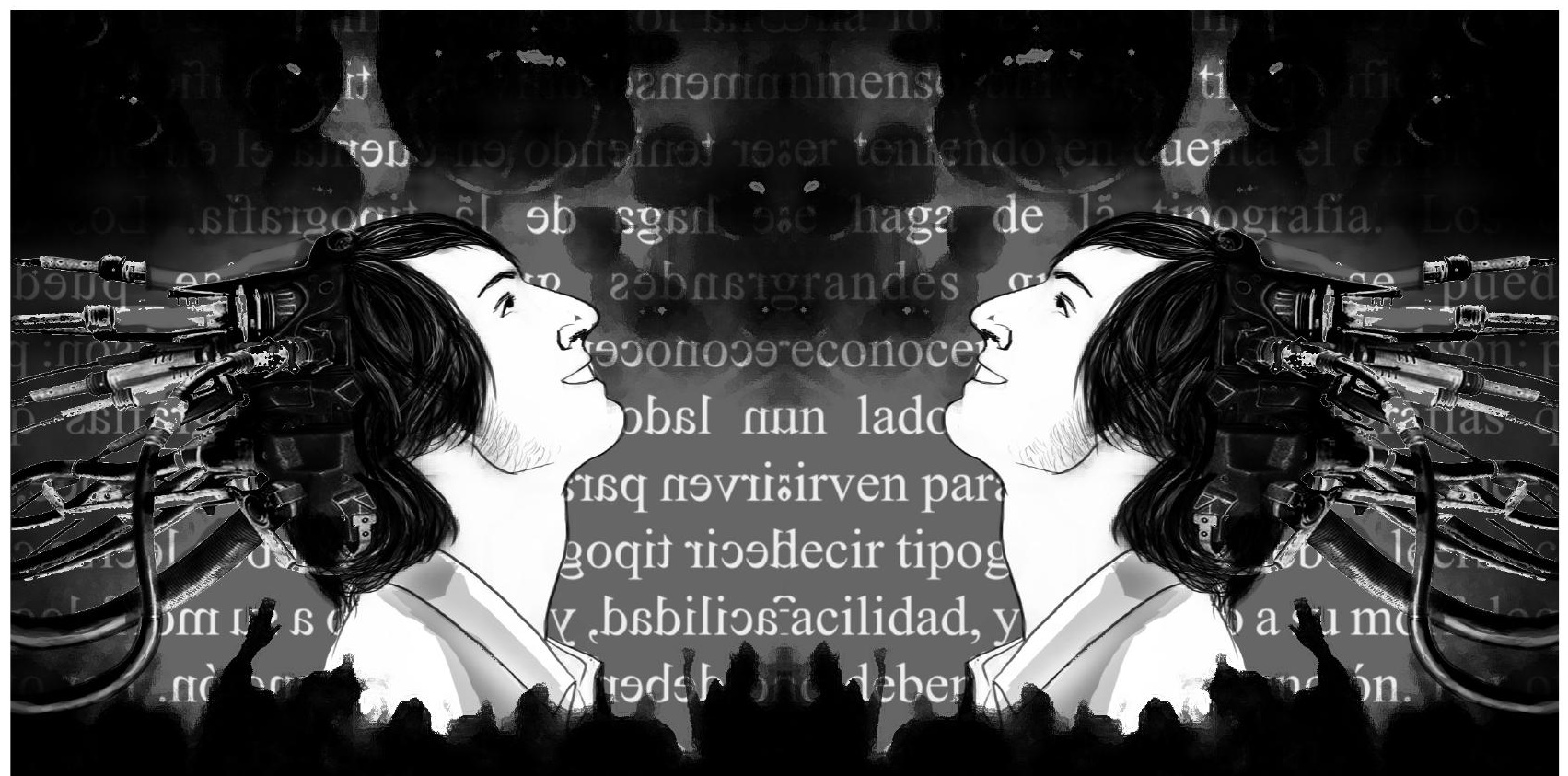


En cada uno de los casos analizados, fue posible identificar quién o quiénes controlaban la agenda de consumo cultural, mediante qué tipo de mecanismos y con qué criterios. En el caso de uno de los jóvenes, por ejemplo, era la madre quien se encargaba de definir la agenda por medio de la adquisición de un equipamiento tecnocultural que garantizaba la permanencia del niño en la casa. El criterio era, entonces, la necesidad de que su hijo tuviera a la mano todo cuanto necesitaba para ocupar el tiempo libre, de tal manera que cuando no permaneciera en el colegio no saliera a la calle, junto a personas que ella no conocía, en un barrio que no colmaba las expectativas sociales de la madre. Así las cosas, para este chico, la televisión -con su programación, sus horarios, sus rutinas- operaba como ordenador de sus otras actividades -el juego y las tareas escolares-, y como dispositivo que lo separaba de espacios como la calle y el barrio. A excepción de la asistencia a cine (la cual disminuye después de haber adquirido el reproductor de video, por lo menos durante los primeros meses), la agenda diseñada por la mamá del niño privilegiaba las prácticas domésticas de consumo, por encima

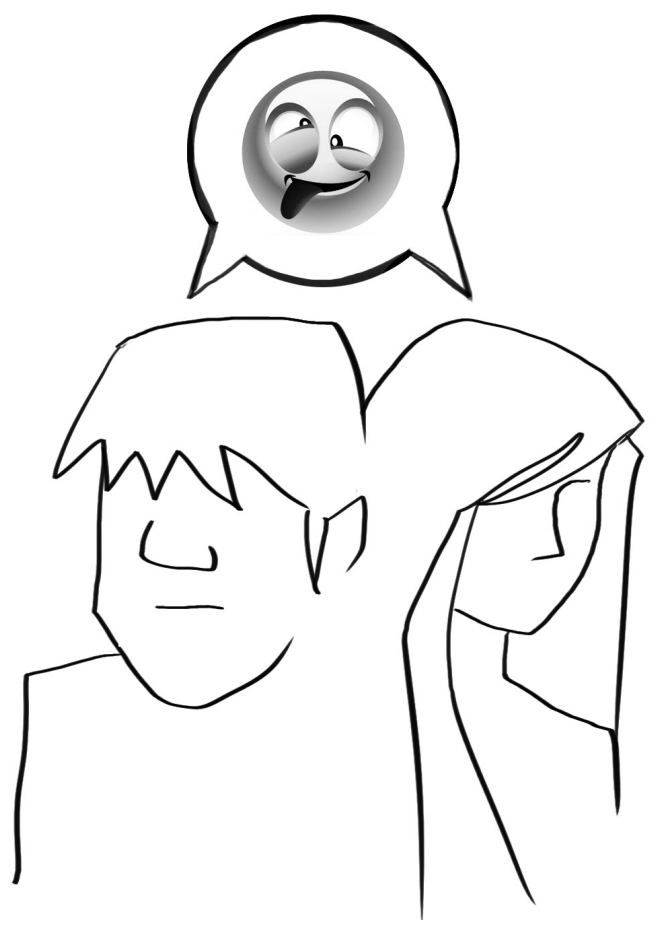
de las que implicaban el acceso a lugares públicos. Como se pudo ver durante la investigación, dos prácticas -el consumo intensivo de televisión y la asistencia periódica al cine- marcaron de manera notoria los hábitos de consumo cultural de este joven.

\section{La biblioteca doméstica: ¿fragmentación o desintegración?}

Desde una perspectiva ilustrada de la formación cultural, se ha considerado la biblioteca como un lugar con aura doble: contiene algo sagrado (los libros) y es un espacio separado tajantemente de las actividades cotidianas. No obstante, los jóvenes no necesariamente ven los libros como objetos sagrados (no todo lo que ellos leen son libros) ni consideran que la biblioteca sea el único lugar donde se pueda leer. En este proceso de desacralización, el desarrollo tecnológico y las dinámicas de ampliación del mercado también han puesto de su parte, no sólo porque la producción impresa se ha ampliado a otros formatos como la revista y han aparecido otros soportes (discos compactos, libros electrónicos) sino porque hoy en día los materiales de lectura se consiguen en muchas partes, desde las librerías especializadas de compra directa hasta las librerías virtuales y las bibliotecas digitales, pasando por el puesto de ventas de la esquina, el supermercado, las ventas de segunda, los aeropuertos, las terminales de transporte. Y como consecuencia de la desacralización del libro, la biblioteca - tanto la institucional como la doméstica - pierde también su aura y se convierte en otro más de los dispositivos tecnoculturales a los que los jóvenes tienen acceso. De hecho, como se pudo constatar en las entrevistas realizadas, la existencia de una biblioteca doméstica - un sitio destinado exclusivamente para albergar librosno fue una constante en los cinco casos estudiados. 
Como lo afirma Sonia Muñoz,

Si la ciudad y la imprenta fueron el entorno y la tecnología que hicieron posible la circulación del libro, el 'hacer vida en casa' volvió sin sentido los templos-biblioteca. Dependiendo del origen social, de la tradición cultural y de los proyectos de los miembros de cada familia, lo escrito ha de reñir su puesto junto a tantos otros objetos de la casa, hoy portadores también de gozo o de signos de distinción (Muñoz, 1995, p. 82).

Todos los jóvenes entrevistados -excepto uno que no era poseedor de libros- preferían consultar sus propios libros en lugar de acudir a la biblioteca de la universidad o de otra institución. Los trámites dispendiosos para cualquier consulta, la planta física poco atractiva, la incomodidad y el no poder tener un contacto directo con todos los libros, son algunas de las razones que explican su falta de interés por las bibliotecas públicas -en particular la de su universidad-.

El hecho de que los estudiantes no se animaran a ir a una biblioteca, es decir, a un lugar diferenciado del mundo cotidiano, a ocuparse de la lectura como actividad exclusiva y excluyente; el que acudieran allí a sacar fotocopias para realizar tareas y no a leer; el que prefirieran tener los libros en el cuarto; y el que la biblioteca no fuera para ellos un lugar 'sagrado', se relaciona con la tendencia a adoptar un modelo de 'confortabilización' condensado en el lema: "todo junto, todo cerca”. Un modelo que permitiría tenerlo todo en casa y proceder con los recursos que se encuentran próximos para así no tener que vivir la aventura del desplazamiento ni correr riesgos en la búsqueda de la información y en el acceso a bienes y servicios. Se trata de un modelo que en la cultura impresa tiene como paradigma el formato revista y en el mundo digital se manifiesta en sitios web como Wikipedia, "el rincón del vago" o monografías.com. En fin, un modelo de 'confortabilización' que provee a los lectores de información condensada, que se puede tener en cualquier lado y leer en cualquier parte.

Lo anterior nos estaría hablando, a su vez, de una tendencia a la domesticación de la producción cultural, en el sentido de que los jóvenes tienden a producir con aquello que tienen en casa, que conocen y encuentran a la mano: las propias experiencias de vida, los medios audiovisuales presentes en su espacio doméstico, las páginas de internet, los libros, periódicos y revistas que encuentran en casa), la música con la que cuentan en esa fuente aparentemente inagotable que es internet. La experiencia de extrañamiento y de riesgo que trae consigo ir a la biblioteca, visitar lugares ajenos o iniciar la lectura de un libro cuyo contenido se desconoce completamente, son situaciones que no encajan dentro de esta lógica de domesticación de la producción cultural, acentuada por la inmediatez en el acceso a la información que permiten las Tics. 
La casa es el sitio desde donde se ejecutan sus trayectos de consumo cultural: desde allí se habla con los amigos a través del teléfono (o del Black berry); en la casa se hacen muchas de las tareas escolares, se leen revistas, se escucha la radio o se mira el noticiero; y estando en ella se puede estar conectado a la red.Y cuando se sale del ámbito doméstico, una cierta lógica de enclaustramiento sigue operando a través del reproductor del celular, el mp3 o el ipod, dispositivos tecnológicos que pretenden crear una barrera visible entre el entorno (la música que no es del gusto propio, las conversaciones inoportunas, el ruido) y la subjetividad. Así, paradójicamente, la lógica de la domesticación, expresada en la accesibilidad a lo global y por lo tanto en la posibilidad de tenerlo todo cerca, produce -a la larga- ese mismo efecto de enclaustramiento ${ }^{18}$ característico en la vida de muchos jóvenes urbanos.

Por otro lado, la tendencia a la confortabilización y domesticación ya caracterizadas, está acompañada por una tendencia a la recepción y uso concurrente de distintos dispositivos mediáticos como el televisor, el teléfono celular y el computador, con sus sonidos, textos e imágenes simultáneos. La declaración de uno de los jóvenes entrevistados resulta muy ilustrativa con respecto a una tendencia que ya se empezaba a develar hace casi tres lustros:

"Con la tecnología uno se va volviendo cómodo. Habla por teléfono acostado mientras ve televisión y le llega información de todas partes. Hace tareas viendo televisión, tiene un periódico al lado, o puede tener el radio prendido. Uno se acostumbra, y le dicen que si uno está loco. Yo siempre hago las tareas acostado, prendo el televisor y me concentro así, o escuchando radio (...) A veces esto se presenta porque suceden al mismo tiempo cosas que son tan chéveres y uno no se quiere perder detalle de ninguna de las dos. Puede coincidir un programa de televisión con una canción en la radio que a uno le gusta (...)".

Esta capacidad para recibir simultáneamente mensajes provenientes de distintas fuentes, nos habla de un hecho significativo. Ya no estamos ante la misma lectura (y escritura) callada, meditativa y solitaria, que sumerge al lector en un ambiente y produce en él un efecto de arropamiento. Nos encontramos ante una lectura interrumpida, salpicada y fragmentada, que concurre en un mismo tiempo y en un mismo espacio con otros ambientes: el computador -que puede integrar medios antes independientes como la radio, el cine, la televisión y la prensa escrita-; la música en los dispositivos de almacenamiento y reproducción cada vez más pequeños y sofisticados; el celular, con sus llamadas, fotografías y mensajes de texto que no se hacen esperar. Todo ello integra una mixtura de medios que compiten entre sí por la atención del usuario; que encajan con ciertas formas de interacción social pero que riñen con otras; que (con)funden las tareas escolares con las charlas entre amigos y superponen el mundo de la vida cotidiana con la vida de los artistas de la farándula o con la de los personajes de mundos ficticios. Uno de los rasgos más significativos de esta forma de lectura es la no renuncia al devenir del entorno: se lee, pero no siempre se pierde contacto con el mundo circundante. Por el contrario, hay una disposición permanente a salirse del texto y regresar a él, en una especie de fuga reiterativa que favorece la inmersión en ambientes que unas veces se relevan, otras se superponen y a veces comparten la atención del que podríamos denominar el "lectovideoyente". 


\section{A modo de cierre: hacia un cambio en el centro de la reflexión}

La investigación "Lecturas y escritures juveniles: entre el placer, el conformismo y la desobediencia” tuvo como eje los siguientes planteamientos: (1) Las prácticas de producción y consumo cultural de los individuos se inscriben en escenarios de interacción social, en cuya dinámica adquieren sentido lo que los sujetos reciben y lo que construyen en el entramado de la vida cotidiana y en un entorno tecnologizado y mediatizado. (2) Los medios de comunicación actúan como ambientes en los que las personas pueden sumergirse. Esta dimensión ambiental de los medios se realiza en contextos culturales específicos y se produce si hay formas de relación social que la hagan posible. Uno de los propósitos de este artículo fue, entonces, mostrar cómo en la articulación entre formas de interacción social y medios de comunicación se juega la eficacia comunicativa y la dimensión expresiva de los mismos.

A partir de allí, se produce un desplazamiento teórico y metodológico: el centro de la reflexión se traslada del análisis del dispositivo tecnológico y los contenidos que canaliza, a las formas de interacción social en las que se articulan los medios y se lleva a cabo la construcción de sentido. Cobra importancia, entonces, la pregunta sobre lo que hacen los jóvenes con los medios a los que tienen acceso, y otras que se derivan de ella: ¿Cuáles son sus modos de relacionarse con los medios de comunicación?, ¿en qué medida los dispositivos tecnológicos (desde el libro hasta los computadores) constituyen ambientes deseables para ellos?, ¿qué tanto se sumergen en dichos ambientes y qué tipo de mixturas resultan de la superposición de unos medios y otros? Abordar preguntas como éstas nos permitiría entender la proximidad y la distancia de los jóvenes frente a las distintas tecnologías de información y comunicación, analizar los modos particulares de uso o recepción, así como proporcionar algunas pistas para entender los modos de relación de los jóvenes con la lectura y la escritura.

Por este camino, nos encontramos con la pregunta sobre los factores que inciden en la constitución de perfiles juveniles de producción y consumo cultural, particularmente en lo relacionado con las prácticas de lectura y escritura. Según lo señalamos, el lugar de la lectura, la escritura y los medios de comunicación audiovisuales en la vida de los jóvenes se va definiendo paulatinamente y tiene una relación directa con la configuración de las formas de socialización en tres ámbitos particulares: la familia, la escuela y el entorno barrial.

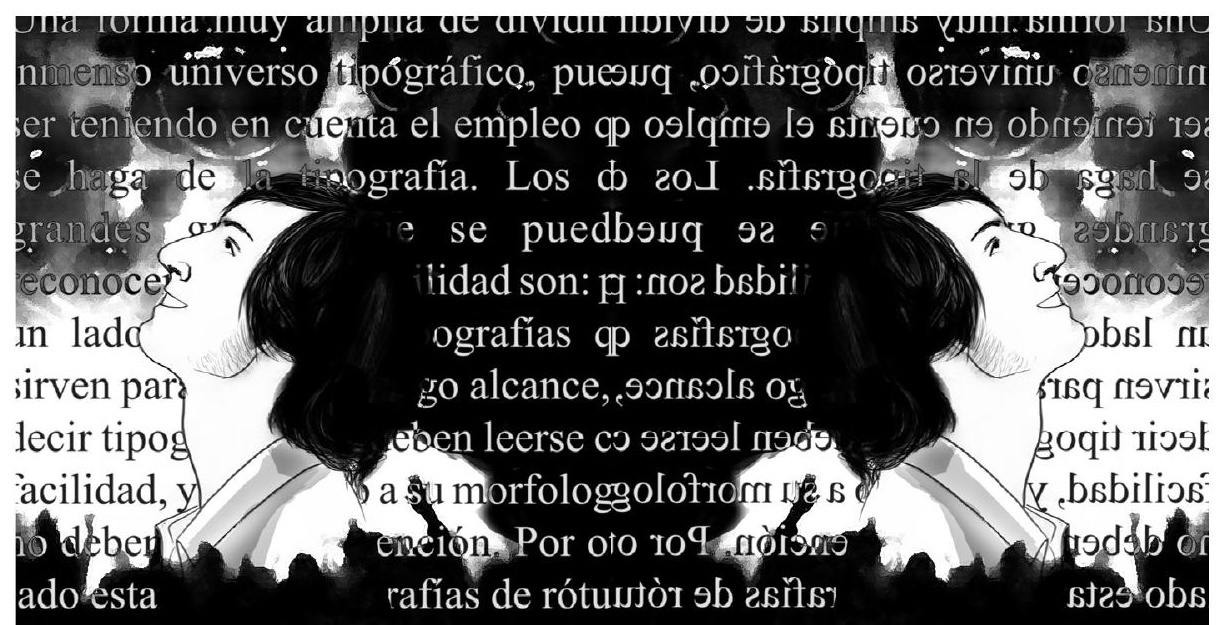


La adquisición de hábitos de lectura y de escritura es el resultado de un proceso que rebasa el dispositivo escolar. Ningún trabajo de investigación o proyecto educativo orientado al estímulo de hábitos de lectura y escritura puede estar desconectado del marco general de las prácticas de producción y consumo cultural desarrolladas por los sujetos. En otras palabras, el estímulo de la lectura y la escritura debe estar articulado a una política cultural integral. Por ello, un problema que debería ser objeto de futuros trabajos de investigación tiene que ver con la agenda cultural doméstica, es decir, el conjunto de estrategias -implícitas o explícitas- que orientan las prácticas de consumo y producción cultural al interior de la familia y que contribuyen a perfilar los gustos, las apetencias y las destrezas de los jóvenes en esta materia. Es necesario profundizar en las maneras como se constituye y los modos como opera dicha agenda, y articular estos resultados al diseño de políticas culturales que integren a la familia como dispositivo de sociabilidad fundamental en la configuración de perfiles juveniles de producción y consumo cultural.

En cuanto a la escuela, a ésta también le compete un papel fundamental en la constitución de dichos perfiles pues, más allá de su función en la apropiación del conocimiento, es un espacio donde se construyen formas de interacción social, al interior de las cuales los jóvenes se van constituyendo como sujetos productores y consumidores de bienes simbólicos. Aunque este artículo no presenta un análisis de los hábitos de lectura y escritura de los jóvenes ni aborda el papel jugado por la escuela en su configuración ${ }^{19}$, es importante señalar aquí la necesidad de trabajar la práctica de la lectura desde la perspectiva de los ambientes. La biblioteca tradicional no es un dispositivo eficaz para el desarrollo de hábitos lectores porque no permite crear ambientes de sumersión en el libro como medio, porque no propicia relaciones sociales que sirvan de anclaje entre los jóvenes y la lectura, porque va en contra vía de las formas de interacción juveniles derivadas de ambientes mediáticos que operan con lógicas distintas y se inscriben en ámbitos muy poco parecidos a los que propicia la biblioteca escolar o el aula de clase, y sobre todo porque hay, por parte de muchos maestros, un total desconocimiento de la manera como lo jóvenes leen y una marcada indiferencia ante sus gustos y apetencias. Algunos intentos se han venido haciendo, pero es necesario multiplicar estos esfuerzos, sobre la base de investigaciones que arrojen nuevas pistas al respecto.

Así mismo, en lo que respecta a la dimensión educativa de las tecnologías informáticas, de nuevo es necesario destacar que la inserción de las tecnologías en un entramado social es lo que determina sus formas de apropiación y que por lo tanto, la clave no está en los dispositivos ni en los contenidos, sino en las relaciones sociales que les dan sentido. La utilización de las tecnologías audiovisuales digitales con fines pedagógicos debe asumir el doble carácter de éstas en tanto herramientas para la producción y transmisión del conocimiento y como instrumentos que deben ser objeto de un proceso de aprendizaje. Pero el desarrollo de estas dos dimensiones -su posibilidad de constituirse en mediaciones cognitivas- depende, en gran medida, de la capacidad del dispositivo escolar para reconocer la dimensión comunicativa de las tecnologías e instaurar formas de socialización que promuevan su uso y le den sentido a su utilización. 


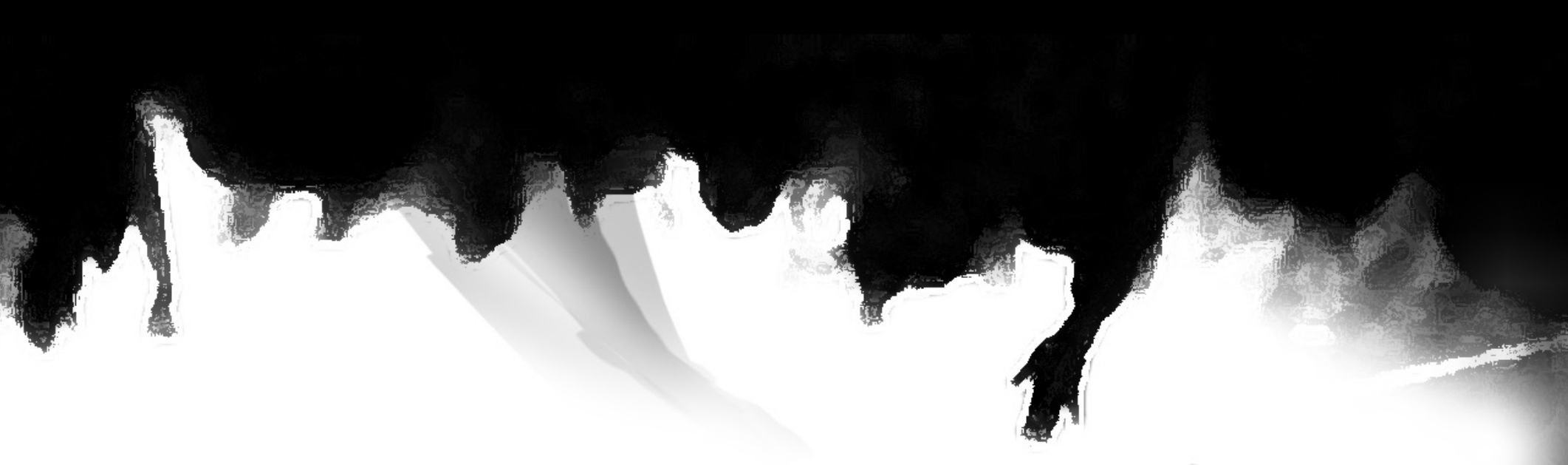

\section{Notas:}

1 Integrante del grupo de investigación Escritura, Tecnología y Cultura. Comunicadora Social, Licenciada en Música y Magíster en Comunicación y Diseño Cultural de la Universidad del Valle. Actualmente realiza el doctorado en Ciencias de la Educación Rudecolombia, Universidad Tecnológica de Pereira.

2 Teóricos, novelistas, poetas, ensayistas e incluso periodistas hacen -desde hace varias décadas- enérgicos llamados que cabalgan entre las evocaciones nostálgicas y el anuncio de una catástrofe cultural por el predominio de la imagen frente a la cultura escrita. Muchos educadores manifiestan su preocupación y su desconcierto ante la falta de habilidades de los estudiantes para la lectura y la escritura: "los alumnos no saben leer, no escriben correctamente, no saben emplear los signos de puntuación, ¡ni siquiera conocen la ortografía!”. En las conversaciones cotidianas son frecuentes afirmaciones del sentido común, al estilo de “...los jóvenes de hoy en día ya no leen” o “¡la televisión es la culpable de que a los niños no les guste la lectura!”. A su turno, la empresa privada, los organismos estatales y las organizaciones no gubernamentales consideran un imperativo emprender vigorosas campañas para promover la lectura, porque ven con preocupación el escaso interés de niños y adolescentes frente a estas prácticas...

3 Aunque todo acto de consumo es en sí mismo una práctica cultural y por lo tanto la expresión 'consumo cultural' resulta altamente redundante, se utiliza aquí esta denominación, por cuanto interesa hacer referencia explícita al consumo de bienes culturales o simbólicos, tales como: programas de radio y televisión, diarios, libros, revistas y otros materiales impresos, discos, textos electrónicos de diverso tipo, exposiciones, conciertos, películas de cine, videos y representaciones de artes escénicas, producidos por instituciones y actores de la cultura especializada, así como otro tipo de bienes simbólicos generados al interior de dinámicas locales de comunicación, como podrían ser las diversas expresiones de la cultura popular, las programaciones culturales al interior de la vida universitaria, etc. Como puede apreciarse, el término cultura especializada no alude de manera exclusiva a la "alta cultura", sino que, además de incluirla, la sobrepasa, pues comprende fundamentalmente los productos elaborados por las denominadas industrias culturales.

En cuanto a la noción de prácticas de producción cultural, alude a la puesta en ejercicio de competencias particulares para la producción de bienes simbólicos como: la literatura, el cine, las artes plásticas, el ballet, la música, el teatro, pero también la narración oral, la escritura no literaria, la fotografía, la caricatura, el grafiti, el video, la música folclórica y popular, la artesanía, el arte callejero, la danza, el humor, en fin, cualquier práctica que implica la presencia de actores sociales en un contexto social y en un espacio de interacción y de comunicación concretos.

4 La investigación - cuyos resultados se presentan en un libro publicado por la Universidad del Valle en 2008- se realizó entre los años 1997 y 1999 y estuvo inscrita en la Maestría en Comunicación y Diseño Cultural de la Escuela de Comunicación Social de la misma universidad. En ese sentido, tanto su vigencia como su pertinencia podrían ponerse en cuestión, entre otras razones porque los avances en el campo de las nuevas tecnologías se producen de manera acelerada. Es cierto que en el momento de realizarse el trabajo de campo algunos dispositivos como el mp3 y el ipod, los mensajes de texto de los teléfonos celulares, así como las cámaras y las grabadoras incorporadas a estos últimos, no existían aún. Sin embargo, como se puede observar en el mencionado libro, lo que estos nuevos dispositivos han hecho es reforzar algunos de los efectos que ya se percibían en artefactos anteriores, conocidos y usados por los jóvenes entrevistados. Además, las formas de relación de los jóvenes con las lecturas y escrituras, el modo con se van configurando hábitos y rutinas relacionados con estas prácticas, las tensiones entre unas formas de consumo cultural ligadas a la cultura escrita y otras ligadas a la tecnocultura contemporánea (Ulloa y Carvajal 2006), los retos que para la escuela representan tales tensiones, todo ello sigue teniendo vigencia en el momento de publicación del presente artículo. 
5 Ver IBÁÑEZ, JESÚS, Más allá de la sociología, Siglo XXI, Madrid, 1979, capítulo V.

6 Ver, Ruiz, José e Ispizua, María Antonia, La entrevista en profundidad, en Descodificación de la Vida Cotidiana, Universidad de Bilbao, 1989.

7 Nos referimos aquí a lo planteado por Bourdieu en cuanto a que las clases sociales no sólo ocupan un determinado lugar de la sociedad por el capital económico que poseen, sino también por su capital cultural. Este último es para él un capital legítimo, históricamente constituido, que constituye un factor de distinción entre las clases. Bourdieu hace también la distinción entre lo que denomina el capital de origen -entre el que se encuentra el capital heredado que marca fuertes diferencias y desigualdades entre las clases- y un capital de llegada, adquirido básicamente por medio del tránsito por la formación escolar. El concepto de capital cultural es desarrollado por el autor en varias de sus publicaciones, entre ellas, La Distinción, Taurus Humanidades, Madrid, 1981.

8 Cuando hago alusión a las funciones que en situaciones de desarraigo o de desprendimiento pueda cumplir la escritura, me refiero a la posibilidad de que algunas personas encuentren en ella una forma de resistencia subjetiva a la nueva situación o una estrategia de vinculación que posibilita la creación de nuevos nexos sociales. El intercambio permanente de cartas con personas que han quedado lejos, los textos escritos como una manera de desahogo espiritual y como una táctica de aislamiento o resistencia a la constitución de nuevos vínculos, y el paso a una escritura que refleja el paulatino proceso de adaptación a las nuevas circunstancias, son algunos ejemplos de esas funciones que puede llegar a cumplir la escritura. Algunas jóvenes, por ejemplo, acostumbran tener una libreta personal donde escriben textos a partir de sus pensamientos y sentimientos -que rara vez muestran alguien- en los cuales evocan eventos pasados, personas a quienes extrañan o situaciones vividas que se recuerdan con nostalgia. Así mismo, practican otro tipo de escritura que sí es socializada, es decir, que tiene el propósito de expresar a otros (casi siempre a sus amigas del colegio) sus pensamientos y emociones. Los destinatarios de estos textos pueden ser personas a quienes ya no es posible ver con la misma frecuencia, u otras a quienes están empezando a conocer y con quienes se comienzan a tejer nexos afectivos, significativos en los periodos de adaptación o en ciertas etapas de transformación como lo es el paso de la infancia a la adolescencia. En cuanto a la lectura, se pueden mencionar aquellos casos en los que el compartir gustos lectores (ciertos textos, ciertos autores, ciertos formatos) constituye una forma de comunicación, bien sea con personas que están lejos (padres, familiares jóvenes o amigos) o con aquellas que se empiezan a conocer en los nuevos espacios de interacción social que se habitan.

9 Vale la pena aclarar que en ningún momento se quiere hacer aquí una apología del autoritarismo o de la represión como una manera de formar a los jóvenes en la autonomía y la reflexión crítica de la realidad que los rodea, sino abordar el problema de la constitución de las subjetividades desde una perspectiva crítica, pues como lo señala Pérez, "lo más relevante, de la nueva subjetividad, promovida por el mercado totalitario, diversificado y comunicativo, es la socialización temprana, inmediata, que tiende a opacar la situación edípica y a evitar la formación de una mismidad, de un interior privado de rebeldía y fantasía promoviendo la formación de un aparato psíquico sin complejidad interna, volcado hacia el exterior, sin pretensión de individuación, con una ansiedad permanente de identificación externa, sin facultad crítica, con una autonomía precaria” (p. 85). De igual manera, es necesario aclarar que al hacer referencia a la importancia de la escuela como escenario donde se tejen relaciones sociales que van más allá de la tarea educativa "formal" de la escuela, no se pretende ignorar que los procesos de apropiación de conocimientos que se dan en su interior se realizan sobre la base de la existencia de ciertos modos de relación social.

10 Sin embargo, con relación al empleo de los dispositivos audiovisuales habría que agregar algo más: su emergencia en el mundo escolar se podría leer como una manera de eludir -por lo menos tentativamente- los rigores, las dificultades y las complejidades de las prácticas de lectura y escritura. En muchas ocasiones, como lo señala Jesús Martín-Barbero, ante la resistencia de los jóvenes a una educación que se basa exclusivamente en los principios y las técnicas de la cultura letrada, la escuela opta por introducir en su espacio de dominio los medios de comunicación; pero esa inserción implica, en la mayoría de los casos, un uso instrumental, pues "para muchas escuelas la presencia de la videograbadora o el computador forma parte del conjunto de gestos que es indispensable hacer para que el rostro, o mejor la fachada, de la educación cambie dejando el resto igual. Son gestos dirigidos más hacia afuera que hacia adentro; es el prestigio del colegio lo que se vería comprometido por la ausencia de ciertas tecnologías comportadoras en sí mismas de un status moderno y por tanto modernizador”. Martín-Barbero, Jesús, Nuevos Modos de Leer, En Magazín Dominical, El Espectador, N474, Santafé de Bogotá, 24 de mayo de 1992, p. 21.

11 Aludimos aquí al concepto de "tecnología intelectual” desarrollado por Pierre Levy. Las tecnologías intelectuales son aquellas que una civilización utiliza para la producción, la reproducción y la conservación de los conocimientos. Ver Levy, Pierre, La oralidad primaria, la escritura y la informática, en la Revista del Consejo Latinoamericano de Ciencias Sociales, N58, Octubre de 1991.

12 Las nuevas tecnologías de la información y comunicación forman parte de la tecnocultura contemporánea. Al igual que la cultura escrita, la tecnocultura constituye una mediación cognitiva, es decir, un conjunto de conocimientos semánticos y procedimentales, necesario para el acceso y la construcción de otros conocimientos. Para la definición de cultura escrita y tecnocultura contemporánea en tanto mediaciones cognitivas, ver Ulloa y Carvajal (2006). 
13 Retomo aquí algunas observaciones hechas por el profesor González al trabajo titulado "Del olor de la tinta a la digitalización de la palabra: reflexión sobre los cambios y permanencias en la apropiación de una tecnología”, elaborado en el marco de la Maestría en Comunicación y Diseño Cultural”, Carvajal B. Giovanna, Santiago de Cali, 1996.

14 Hoy en día, esas interacciones alrededor de los video juegos se han potencializado con el uso de internet, pues mediante del uso de las redes sociales, el correo electrónico, el chat y la mensajería instantánea, los niños y adolescentes intercambian sus conocimientos sobre esta materia: comandos que permiten ganar la partida, trucos y atajos para optimizar el juego, versiones actualizadas de video juegos, etc.

15 Howard Gardner plantea que los seres humanos somos capaces de entender el mundo de siete modos distintos, que él ha denominado las siete inteligencias humanas. Para él "todos somos capaces de conocer el mundo a través del lenguaje, del análisis lógico-matemático, de la representación espacial, del pensamiento musical, del uso del cuerpo para resolver problemas o hacer cosas, de una comprensión de los demás individuos y de una comprensión de nosotros mismos. Donde los individuos se diferencian es en la intensidad de estas inteligencias - lo que se ha dado en llamar perfil de inteligencias- y se las combina para llevar a cabo diferentes labores, para solucionar problemas diversos y progresar en distintos ámbitos". Ver Gardner, H, La Mente no Escolarizada. Cómo piensan los niños y cómo deberían enseñar las escuelas, Ediciones Paidós Ibérica S.A, Barcelona, 1993, p. 27.

16 A propósito de este tema, es pertinente anotar lo siguiente: las tecnologías audiovisuales a las que los alumnos acceden -en su casa, en la de sus amigos o en espacios públicos de consumo- no requieren de la mediación del adulto, sobre todo en el caso particular de los jóvenes, quienes tienden a ser cada vez más autónomos en lo que respecta a sus prácticas de consumo cultural. El consumo y el uso de las tecnologías audiovisuales de comunicación no opera a partir del modelo de la adultez. La formación en la lectura y la escritura, en cambio, necesita de la mediación adulta: una saber adulto que se constituye en privilegio y que ha de ganarse a costa del descubrimiento de los secretos que encierra el mundo adulto; secretos sistemáticamente separados de la infancia, pero que cada día son menos desconocidos en virtud de la presencia de las tecnologías de la información y de la comunicación.

La autoridad del mundo adulto se construía especialmente mediante el secreto, el misterio y la reserva, los cuales tenían su reverso en los rituales de iniciación al mundo adulto en los que eran revelados. En una sociedad mediática y tecnologizada, que tiende a mostrarlo todo y a hacerlo más transparente, los misterios se han disuelto y con ello parte del mecanismo de prestigios del mundo adulto y sus autoridades.

17 Por equipamiento tecnocultural entendemos aquí el conjunto de dispositivos o artefactos que hacen posible tanto el acceso a mensajes, sean estos de orden sonoro, visual, o verbal, como la conexión con otros y la edición o producción de textos. La radio, el equipo de sonido, el televisor, el teléfono, el fax, el computador, la cámara fotográfica o de video, la video grabadora, así como los medios impresos como el libro, la revista y el periódico, corresponden al equipamiento de uso doméstico, en tanto que el cine, los museos, las bibliotecas, las discotecas, los teatros y los escenarios al descubierto forman parte del equipamiento de uso público. La distinción entre equipamiento cultural de uso público y equipamiento cultural de uso doméstico es propuesta por Sonia Muñoz en el trabajo de investigación ya citado. Ver Muñoz. Sonia, El Ojo, el Libro y la Pantalla. Consumo Cultural en Cali, op. cit, p. 33.

18 Es importante anotar también que al lado de las tendencias a la confortabilización y domesticación de la cultura existe una dinámica complementaria. Se trata de la vocación de fuga y escape de los jóvenes urbanos con respecto a sus propias vidas familiares. Esa vocación de fuga se expresa en dos movimientos: la urgencia de estar en la calle y la urgencia de estar en el cuarto. La fuga hacia afuera (los amigos, el barrio, el colegio, la calle, el cine, la vida nocturna) y la fuga hacia adentro (la soledad del cuarto donde se videojuega, se chatea, se escribe o se lee en la pantalla, se escucha música, se ve televisión); y, en medio de las dos, la posibilidad de conectarse con los otros sin moverse del propio sitio a través del teléfono o la internet, constituye la clave para entender esa doble tendencia al sedentarismo (enclaustramiento en casa) y al nomadismo urbano que caracteriza a muchos jóvenes de hogares crecientemente confortables.

19 Este tema es abordado en los capítulos II y III del libro donde se presentan los resultados de la investigación. 


\section{Referencias}

Barthes, Roland, (1981). El Susurro del Lenguaje. Más allá de la Palabra y la Escritura, Ediciones Paidós, Barcelona.

Bourdieu, Pierre, (1981). La Distinción, Taurus, Madrid.

Carvajal, Giovanna, (2008). Lecturas y escrituras juveniles: entre el placer, el conformismo y la desobediencia, Programa Editorial Universidad del Valle, Cali.

Gardner, Howard, (1991).La Mente no Escolarizada. Cómo piensan los niños y cómo deberían enseñar las escuelas,

Ediciones Paidós, Barcelona.

González, Julián, (1997). “Imágenes Sociales de la Tecnología”, ponencia presentada en el Seminario de Historia Social de las Ciencias, Escuela de Filosofía, Universidad del Valle, Cali.

Ibáñez, Jesús, (1979). Más Allá de la Sociología, Siglo XXI, Madrid.

Levy, Pierre, (1991). "La Oralidad Primaria, la Escritura y la Informática”,

en Revista del Consejo Latinoamericano de Ciencias Sociales, $N^{\circ} 58$, octubre.

Martín-Barbero, Jesús, (1987).”Nuevos Modos de Leer”, En Magazín Dominical, El Espectador, N474, Santafé de Bogotá, 24 de mayo de 1992.

McLuhan, Marshall, La Comprensión de los Medios como las Extensiones del Hombre, Editorial Diana, México DF, 1969 (10ª impresión).

Muñoz, Sonia, (1995). El ojo, el Libro y la Pantalla. Consumo cultural en Cali, Editorial de la Facultad de Humanidades de la Universidad del Valle, Santiago de Cali.

Ong, Walter, (1994). Oralidad y Escritura. Tecnologías de la palabra, Fondo de Cultura Económica, Santafé de Bogotá.

Parra, Rodrigo, (1996). Escuela y Modernidad en Colombia. La Universidad, Tomo IV, Tercer Mundo Editores, Colombia.

Pennac, Daniel, (1993). Como una novela, Grupo Editorial Norma, Santafé de Bogotá.

Pérez, Carlos, (1996). Sobre la Condición Social de la Psicología, Psicología-Epistemología-Política,

LOM Ediciones, Universidad ARCIS, Chile.

Piscitelli, Alejandro, (1995). Ciberculturas en la Era de las Máquinas Inteligentes, Paidós, Buenos Aires.

Ruiz, José e Ispizua, María Antonia, (1989).La Entrevista en profundidad, en Descodificación de la Vida Cotidiana,

Universidad de Bilbao.

Silva, Renán, (1998)."El Público o el Nuevo Imaginario de la Escritura”, Revista de la Universidad del Valle, Abril. Nº19.

Ulloa, Alejandro y Carvajal, Giovanna, (2006). Cultura Escrita, conocimiento y tecnocultura. El Marco teórico de una investigación exploratoria en la Universidad del Valle, en Revista Nexus, No 2, Escuela de Comunicación Social, Universidad del Valle.

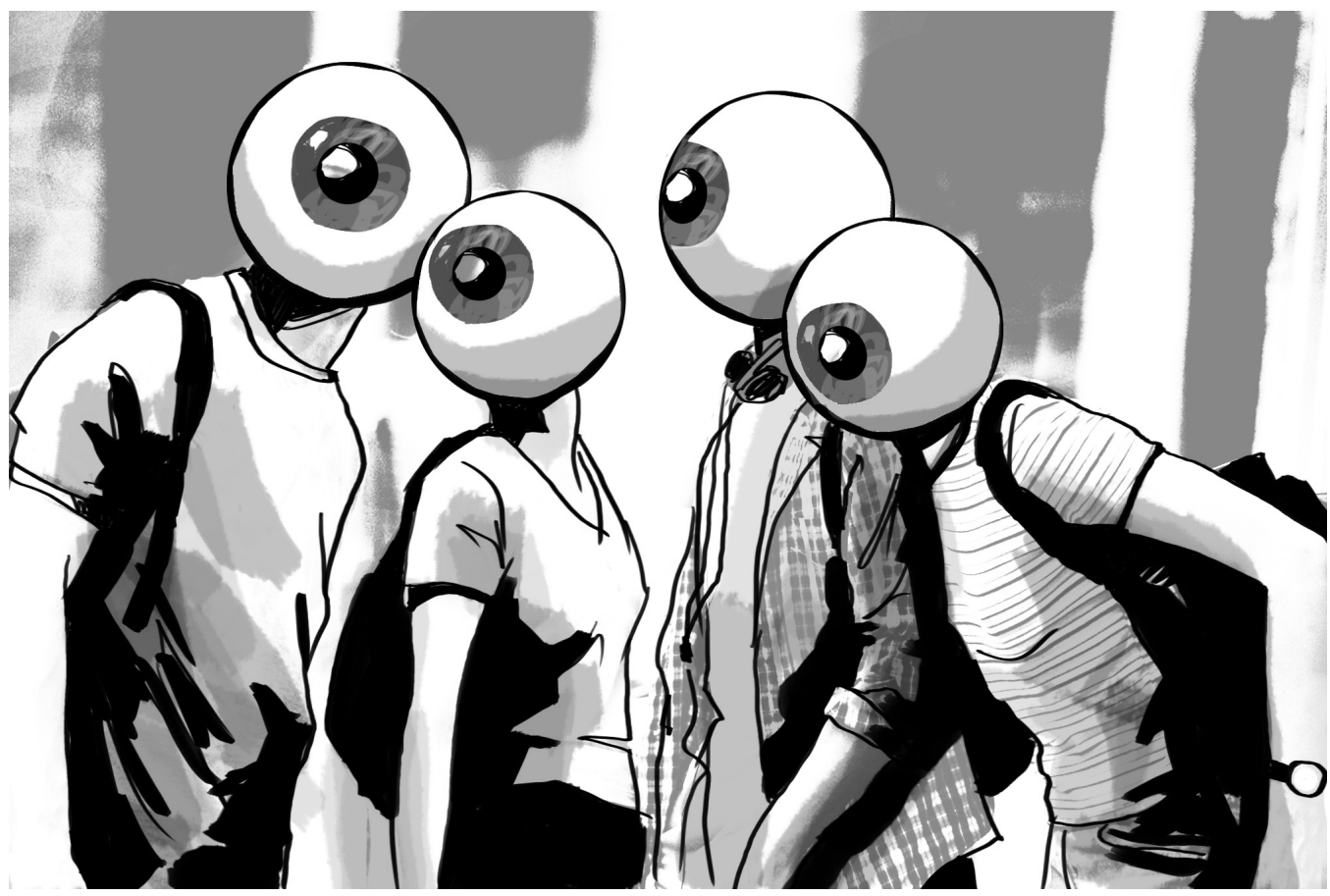

